\title{
A Model for the Flow Stress and Strain Rate Sensitivity in a Refractory Metal
}

\author{
R.E. Reed-Hill and Tuling $\mathrm{Zhu}^{*}$ \\ Materials Science and Engineering, \\ University of Florida, Gainesville, FL 32611 \\ * Changchun Institute of Optics and Fine Mechanics of the \\ Chinese Academy of Sciences, Changchun, P.R. of China.
}

\section{CONTENTS}

\begin{tabular}{|c|c|c|c|}
\hline & Page & & Page \\
\hline ABSTRACT & 94 & THE RELATION OF THE PRESENT MODEL TO & \\
\hline A BRIEF REVIEW OF DYNAMIC STRAIN AGING & 94 & EARLIER DISLOCATION DYNAMICS THEORY & 102 \\
\hline PRIOR THEORIES OF DYNAMIC STRAIN-AGING & 94 & The Temperature Dependence of the Dynamic & \\
\hline The Cottrell Theory of Dynamic Strain-Aging & 94 & Strain-Aging Components of the Stress & 103 \\
\hline The McCormick Theory & 95 & The Strain-Rate Sensitivity & 105 \\
\hline BCC Interstitial Atom Systems & 96 & EMPIRICAL OBSERVATIONS CONCERNING THE & \\
\hline The van den Beukel Theory of Dynamic & & STRAIN RATE SENSITIVITY & 105 \\
\hline Strain-Aging & 96 & Test of the Theory Using the Niobium-Oxygen & \\
\hline A NEW APPROACH TO THE THEORY OF DYNAMIC & & Data of Fries et al. & 106 \\
\hline $\begin{array}{l}\text { STRAIN-AGING } \\
\quad \text { The Significance of Strain-Aging Studies Made }\end{array}$ & 97 & $\begin{array}{l}\text { The Dynamic Strain-Aging Contribution } \\
\text { The Dynamic Strain-Aging Contribution to the }\end{array}$ & 106 \\
\hline Under Stress & 97 & Strain-Rate Sensitivity & 108 \\
\hline The Kinetics of the Yield Point Return when & & Strain-Aging under Stress & 111 \\
\hline Measured under Load & 98 & FUTURE WORK TO EXPAND THE MODEL TO HIGHER & \\
\hline Cottrell Strain-Aging & 99 & TEMPERATURES & 113 \\
\hline Comments on the Cottrell-Bilby Equation & 99 & DISLOCATION DRAG & 114 \\
\hline The Harper Equation & 99 & Experimental Evidence in Support of Dislocation & \\
\hline An Alternate Form for the Bolling-Harper & & Drag & 114 \\
\hline Equation for an Interstitial Solute & 100 & Comments on the Role of Dislocation Drag in the & \\
\hline Additional Support for the Delobelle and & & Portevin-LeChatelier Effect & 116 \\
\hline Oytana Conclusions & 100 & INCLUSION OF DISLOCATION DRAG THEORY IN & \\
\hline CONCLUSION FROM STRAIN AGING STUDIES & 101 & THE MODEL & 116 \\
\hline NEW THEORY OF DYNAMIC STRAIN-AGING & 101 & REFERENCES & 116 \\
\hline
\end{tabular}




\section{ABSTRACT}

Within the past several years a model for a refractory metal such as niobium has been developed, that is capable of describing the dependence of the flow stress on both the temperature and the strain rate. It is also capable of describing the yield point return kinetics when strain aging takes place under stress. Since all commercially available grades of niobium contain finite amounts of oxygen in solid solution, any useful model should consider the effects of this interstitial. In particular the model must properly account for dynamic strain aging, DSA, above ambient temperatures. Thus, as a starting point the subject of DSA will be reviewed.

It will be demonstrated that with the use of strainaging studies made on specimens aged under a constant load, and a hypothesis due to Sleeswyk, it is possible to develop a simple theory of DSA. The key contribution of the aging under load experiments is that in this type of test the specimens deform plastically as they age. Thus, kinetics studies made on specimens aged under load are performed under dynamic deformation conditions closely related to those existing during DSA. Sleeswyk's hypothesis, which also forms the basis for the current theories of DSA due to McCormick and to van den Beukel, is predicated on the assumption that as a dislocation moves across a slip plane its motion is interrupted by obstacles where it waits for thermal activation in order to proceed. Sleeswyk points out that while a dislocation is thus stopped it should be subject to strain-aging, with the degree of pinning the dislocation receives as a function of the arrest time and the diffusion coefficient and concentration of the solute. Furthermore, the literature in the area of strain-aging under load, suggests that the aging kinetics for both Snoek and Cottrell strain-aging are similar to those reported for conventional static strainaging experiments. Thus, the total flow stress in a specimen deforming under conditions of DSA can be considered to consist of two parts; one expected in the absence of DSA, the other due to the combined effects of Snoek and Cottrell aging, each of which can be estimated from a prior knowledge of the kinetics of strainaging under load.

\section{A BRIEF REVIEW OF DYNAMIC STRAIN-AGING}

The existence of DSA has been recognized for many years. Several of its aspects and, in particular, the Portevin-Le Chatelier effect have been studied in considerable detail. The general significance of DSA, however, can be safely stated to have been generally ignored. This in spite of the fact that, in 1952, Lubahn /I/ clearly stated that strain-aging could affect, in one way or another, the mechanical behavior of most of our common commercial metals, and that possibly it influences the results of all phases of mechanical testing. It is also not generally recognized that in the temperature range where many commercial metals are used, the largest part of their strengths may come from DSA. A major factor in producing this unfortunate state of affairs is that a simple model capable of rationalizing all the complexities of DSA has not been available. It is the purpose of this paper to show that it is now possible to reach such an understanding. With this in mind, a short summary of DSA theories will be presented.

\section{PRIOR THEORIES OF DYNAMIC STRAIN-AGING}

\section{The Cottrell Theory of Dynamic Strain-Aging}

This theory /2-4/ considers DSA only in terms of one of its most visible aspects: the Portevin-Le Chatelier effect $/ 5 \%$ It attempts to determine the conditions that control the onset of serrations on a stress-strain curve by assuming that serrations appear when the dislocation velocity becomes large enough to exceed the critical drag stress. This critical velocity, $v_{c}$, is given by

$$
\mathrm{v}_{\mathrm{c}}=4 \mathrm{D} / 1
$$

where $D$ is the solute diffusion coefficient and 1 the effective radius of the solute atmosphere associated with the dislocation. Since above this velocity the stress decreases with an increase in the dislocation velocity, it is logical to conclude that $v_{c}$ represents a critical condition for the appearance of serrations on a stress-strain curve.

If it is now assumed that the Orowan equation is valid we have

$$
\dot{\epsilon}=\phi \rho_{\mathrm{m}} \mathrm{b} \mathrm{v}_{\mathrm{c}}=\frac{4 \phi \rho_{\mathrm{m}} \mathrm{bD}}{\mathrm{l}}
$$

where $\dot{\epsilon}$ is the applied strain rate, $\phi$ is a Schmid orientation factor, $\rho_{\mathrm{m}}$ is the mobile dislocation density, $b$ the Burgers vector, $D$ the solute diffusion coefficient, and 1 the radius of the dislocation atmosphere. The dislocation density is normally considered to be a function of the strain, $\epsilon$, in the form 


$$
\rho_{\mathrm{m}}=\mathrm{N} \epsilon^{\beta}
$$

where $N$ and $\beta$ are constants. In addition, in substitutional alloys where diffusion occurs by a vacancy mechanism, the diffusion coefficient is also considered to be a function of $\epsilon$. Plastic strain is believed to create vacancies at such a rapid rate that the thermal equilibrium vacancy concentration becomes negligible in comparison with that resulting from the strain. The assumed relationship between vacancy concentration and strain is

$$
\mathrm{C}_{\mathrm{v}}=\mathrm{K} \epsilon^{\mathrm{m}}
$$

where $C_{v}$ is the vacancy concentration and $K$ and $m$ are constants. Thus the diffusion equation can be written

$$
\mathrm{D}=\mathrm{D}_{0} \mathrm{~K} \epsilon^{\mathrm{m}} \exp -\mathrm{Q}_{\mathrm{m}} / \mathrm{kT}
$$

where $D$ is the diffusion coefficient, $D_{0}$ the frequency factor, $\epsilon$ the strain, $K$ and $m$ constants and $Q_{m}$ the vacancy migration energy.

On the basis of the above it is possible to write the following equation

$$
\epsilon_{\mathrm{c}}^{\beta+\mathrm{m}}=\frac{1 \epsilon \exp \mathrm{Q}_{\mathrm{m}} / \mathrm{kT}}{4 \phi \mathrm{bNKD} \mathrm{D}_{0}}
$$

where $\epsilon_{\mathrm{c}}$ is the critical strain for the appearance of serrations on the stress-strain curve of a substitutional alloy. Equation 6 suggests experiments for the determination of the parameters $\beta+m$ and $Q_{m}$. For example, an isothermal plot of $\ln \dot{\epsilon}$ versus $\ln \epsilon_{\mathrm{c}}$ should be linear with a slope of $\beta+\mathrm{m}$. At the same time, a plot of $\ln \epsilon_{\mathrm{c}}$ against $1 / T$ made at constant $\dot{\epsilon}$ should yield the vacancy migration energy $Q_{m}$. Such plots have given values of these parameters in a number of alloy systems in quite reasonable agreement with those obtained by other means $/ 4,6-9 /$. While the cottrell theory is thus able to predict both the strain-rate and the temperature dependence of the critical strain, it fails when it comes to predicting $\epsilon_{\mathrm{c}}$ itself $/ 10 /$. Using reasonable values for the dislocation density, the vacancy concentration and the atmosphere radius, 1, leads to a critical strain in error by several orders of magnitude.

\section{The McCormick Theory}

The inability of the Cottrell theory to predict $\epsilon_{\mathrm{c}}$ in fcc metals led McCormick to propose an alternative theory $/ 10-12 \%$. McCormick's theory is also based on the assumption that dislocations move discontinuously, which leads to a dislocation velocity, $v$,

$$
v=\frac{L}{t_{f}+t_{w}}
$$

where $\mathrm{L}$ is a measure of the average distance between obstacles, $t_{f}$ the mean time of flight between obstacles and $t_{w}$ the mean time that the dislocations wait in front of obstacles for thermal activation. McCormick also uses Sleeswyk's hypothesis /13/ that during the waiting time, $t_{w}$, mobile solute atoms could be drawn to it. Specifically, McCormick assumes that serrations appear on the stress-strain curve when $t_{w}$ becomes equal to $t_{a}$, the time needed to lock the dislocation. In this case, the critical dislocation velocity for the appearance of serrations becomes

$$
\mathrm{v}_{\mathrm{c}}=\mathrm{L} / \mathrm{t}_{\mathrm{a}}
$$

where $\mathrm{L}$ is a mean distance between obstacles and $t_{a}$ the time required to age or lock the dislocations. In order to evaluate $t_{a}$, McCormick assumes a CottrellBilby $/ 14 /$ time to the two-thirds power law

$$
1 / \mathrm{t}_{\mathrm{a}}=\left(\alpha \frac{\mathrm{C}_{0}}{\overline{\mathrm{C}}_{1}}\right)^{\frac{\pi}{2}} \frac{3 \mathrm{U}_{\mathrm{m}} \mathrm{D}}{\mathrm{kTb}^{2}}
$$

where $C_{1}$ is the solute concentration at the dislocation needed to lock it, $\mathrm{C}_{0}$ the original solute concentration, $\mathrm{U}_{\mathrm{m}}$ the binding energy between solute and dislocation, $\alpha$ a constant equal to about 3 , and $\mathrm{D}$ the solute diffusion coefficient.

On the assumption that both the dislocation density, $\rho_{\mathrm{m}}$, and the vacancy concentration, $\mathrm{C}_{\mathrm{v}}$, are functions of the strain as expressed in Eqs. 3 and 4, McCormick's assumption leads to a critical strain equation for a substitutional solute of the form

$$
\epsilon_{\mathrm{c}}^{\mathrm{m}+\beta}=\left(\frac{\mathrm{C}_{1}}{\alpha \mathrm{C}_{0}}\right)^{3 / 2} \frac{\dot{\epsilon} \mathrm{kTb} \exp \mathrm{Q}_{\mathrm{m}} / \mathrm{kt}}{3 \dot{\phi} \mathrm{NKU} \mathrm{U}_{\mathrm{m}} \mathrm{D}_{0} \mathrm{~L}}
$$

When this relationship is compared to that of Cottrell's theory we find that

$$
\begin{aligned}
& \epsilon_{c_{M c C o r m i c k}^{m+\beta}}^{m+\beta}=\frac{4}{3}\left(\frac{C_{1}}{\alpha C_{0}}\right)^{3 / 2}\left(\frac{k T}{U_{n l}}\right)\left(\frac{b}{1}\right) \times \\
& \times\left(\frac{b}{L}\right) \epsilon^{m+\beta} \text { Cottrell }
\end{aligned}
$$

It is interesting to estimate the difference between McCormick's $\epsilon_{\mathrm{c}}$ and that of Cottrell. For this purpose 
we use parameter values suggested by McCormick $/ 10 /$. Thus he has used a value of $1=10 \mathrm{~b}$ and references Cottrell /15/. For $\mathrm{U}_{\mathrm{m}}$ he suggests $0.5 \mathrm{eV}$ based on Fleisher's $/ 16 /$ measurements. McCormick also takes $\mathrm{L}$ as approximately $10^{-5} \mathrm{~cm}$. For $\mathrm{C}_{1}$ he uses unity. Assuming room temperature where $\mathrm{kT}$ is about $1 / 30 \mathrm{eV}$, we have

$$
\epsilon_{{ }^{\mathrm{M}} \mathrm{m} \text { Cormick }}^{\mathrm{m}+\beta}=\frac{6.8 \times 10^{-6}}{\mathrm{C}_{0}^{3 / 2}} \varepsilon^{\mathrm{m}+\beta}{ }^{\mathrm{c}} \text { Cottrell }
$$

In substitutional fcc alloys that have been investigated in detail by McCormick and others, the solute concentration is normally high and of the order of $10^{-1}$. Substituting $10^{-1}$ for $C_{0}$ in Eq. 12 and taking $\mathrm{m}+\beta=2$ gives a McCormick critical strain about $10^{-2}$ times that predicted by the Cottrell theory. This difference is about that needed to make the Cottrell critical strain correlate with experimental observations.

\section{BCC Interstitial Atom Systems}

In bcc interstitial alloy systems diffusion occurs by jumping of interstitial atoms between interstitial sites. Since this form of diffusion is independent of the vacancy concentration, the Cottrell critical strain becomes

$$
\hat{\epsilon}_{\mathrm{c}}^{\beta}=\frac{1 \dot{\epsilon} \operatorname{expQ} / \mathrm{kT}}{4 \phi \mathrm{bND}_{0}}
$$

where $Q$ is the activation energy for the diffusion of the interstitial solute and $D_{0}$ is the interstitial diffusion frequency factor. The corresponding McCormick critical strain is

$$
\epsilon_{\mathrm{m}}^{\beta}=\left(\frac{\mathrm{C}:}{\alpha \mathrm{C}_{0}} !^{3 / 2} \frac{\dot{\epsilon} \mathrm{bkT} \operatorname{expQ} / \mathrm{kT}}{3 \phi \mathrm{NLU} \mathrm{U}_{\mathrm{m}} \mathrm{D}_{0}}\right.
$$

At the same time the equivalent expression for Eq. (11) giving the difference between the two measures of the critical strain is

$$
\begin{aligned}
& { }^{{ }^{c}}{ }_{{ }^{M} \text { McCormick }}=\frac{4}{3} i\left(\frac{C_{1}}{\alpha C_{0}}\right)^{3 / 2}\left(\frac{k T}{U_{n 1}}\right) \times \\
& \times\left(\frac{\mathrm{b}}{1}\right)\left(\frac{\mathrm{b}}{\mathrm{L}}\right) \epsilon_{{ }_{\mathrm{c}} \text { Cottrell }}^{\beta}
\end{aligned}
$$

\section{The van den Beukel Theory of Dynamic Strain-Aging}

While McCormick is apparently able to predict the critical strain for the appearance of serrations on a stress-strain curve as well as the temperature and strainrate dependence of $\epsilon_{\mathfrak{c}}$, his theory does not treat other important aspects of dynamic strain-aging such as the yield stress plateau, abnormal and rate dependent work hardening, flow stress transients that occur on changing the strain-rate, and the development of small or negative strain-rate sensitivities. In an effort to create a more universal theory of dynamic strain-aging, van den Beukel /17-19/ also started with Sleeswyk's hypothesis $/ 13 /$ that dislocations can be subject to strain-aging as they wait at obstacles. The major new contribution that van den Beukel adds concerns the activation enthalpy in the thermally activated strain rate equation

$$
\dot{\epsilon}=\dot{\epsilon}_{0} \exp (-\mathrm{H} / \mathrm{kT})
$$

where $\epsilon$ is the strain-rate, $H$ the activation enthalpy, $\dot{\epsilon}_{0}$ a constant and $\mathrm{k}$ and $\mathrm{T}$ have their usual meanings. $\mathrm{He}$ assumes that $\mathbf{H}$ is not only a function of effective stress, $\sigma^{*}$, but also of the solute concentration that a dislocation "sees". Thus, as a dislocation waits at an obstacle and a solute atmosphere builds up around it, the change in solute concentration at the dislocation can be considered to cause a change in the activation enthalpy. In other words van den Beukel assumes that $\mathrm{H}=\mathrm{H}\left(\sigma^{*}, \mathrm{C}\right)$ where $\mathrm{C}$ is the local solute concentration at the dislocation. The value of $\mathrm{C}$ will depend on the time a dislocation waits at an obstacle, $t_{w}$, and the rate of solute drift to the dislocation which depends on the solute diffution coefficient D. $\mathrm{A} \mathrm{t}^{2 / 3}$ relation between concentration and time was also assumed by van den. Beukel who used Friedel's /20/ equation based on the assumption that $\mathrm{Dt}_{\mathrm{w}}$ is small

$$
\mathrm{C}=\mathrm{C}_{0}+\left(\mathrm{KDt}_{\mathrm{w}}\right)^{2 / 3}
$$

where $C_{0}$ is the nominal solute concentration, $K$ is given by

$$
\mathrm{K}=\frac{3 \mathrm{~W}_{\mathrm{m}}}{\mathrm{b}^{2} \mathrm{kT}}\left(\pi \mathrm{C}_{0}\right)^{3 / 2}
$$

and $W_{m}$ is the binding energy of the solute to the dislocation.

The van den Beukel theory will not be considered further, except to point out that it develops relationships for the stress $\sigma^{*}$ as a function of $\dot{\epsilon}$, the stress as a function of the temperature $T$, the conditions for the onset of serrated flow, the effect of DSA on work hardening and the effect of DSA on the strain 
rate sensitivity. This theory is not treated in detail primarily because it is not easily adapted to the present goal, which is to produce a simple workable approach to the problem of plastic flow when deformation involves DSA.

\section{A NEW APPROACH TO THE THEORY OF DYNAMIC STRAIN-AGING}

The van den Beukel theory represents a major advance over the earlier theories of Cottrell and McCormick since it is a general theory that attempts to rationalize all the aspects of DSA rather than a single one, as do the earlier theories. However, the theory of van den Beukel does have the following shortcomings:

1. In the van den Beukel theory $\dot{\epsilon}_{0}$, the pre-exponential term in the thermally activated strain rate equation, i.e. Eq. (16), is treated as a constant. However, both the polycrystalline $\mathrm{Zr}-\mathrm{O}$ data of Baldwin and Reed-Hill $/ 21 /$ as well as the single crystal, $\mathrm{Zr}-\mathrm{O}$ results of Hsu and Higgins /22/ suggest that $\dot{\epsilon}_{0}$ depends on the oxygen concentration. This implies that some features of the van den Beukel analysis involving derivatives of Eq. (16) may be in error because the derivative of the $\dot{\epsilon}_{0}$ term is not considered.

2. A significant problem with the van den Beukel theory is that quantitative predictions of the theory depend on a knowledge of $\partial \mathrm{H} / \partial \mathrm{C}$, the partial derivative of the activation enthalpy with respect to the solute concentration at the dislocation. Data to evaluate this parameter are not generally available.

3. In its original form it treats only strain-aging involving long range migration of solute to dislocations. It is thus specific to the Cottrell form of strain-aging. However, in bcc metals such as niobium containing interstitial solutes, Snoek strain-aging involving the simple reordering of interstitial atoms can be a significant factor in DSA.

4. This theory assumes a Cottrell-Bilby $t^{2 / 3}$ relation /14/ between the solute concentration at the dislocation (i.e., $\mathrm{d} \sigma$ ) and the time. It accordingly does not account for the fact that strain-aging kinetics curves tend to saturate. In other words, at long aging times the concentration of the solute at the dislocation normally approaches a maximum.

5. While the mathematical formulations of the van den Beukel theory appear to be able to elegantly rationalize a number of the aspects of dynamic strainaging, it is difficult to visualize (with the theory) the simple physics of dynamic strain-aging such as why, for example, a negative strain-rate sensitivity is possible.

\section{The Significance of Strain-Aging Studies Made Under Stress}

In a typical static strain-aging experiment, a specimen is prestrained, unloaded, aged and then reloaded and restrained. The increase in flow stress resulting from aging is the quantity measured. In this type of test, aging is usually performed at a higher temperature than that used for the prestraining and restraining of the specimen in order to reduce the time of aging. Because it is difficult to change the temperature of the specimen while the specimen is mounted in a testing machine, the specimen is usually removed from the machine for the aging anneal. Upon being replaced in the testing machine, the alignment of the specimen in its grips is normally altered so that the measurement of the stress at the upper yield point becomes unreproducible. For this reason, many strain-aging studies have reported only the lower yield stress, which is more reproducible. A reproducible upper yield stress is possible if the specimen can be aged in situ on the machine while it is under a small fraction of the load at the end of the prestrain. However, when aged under such a load, a specimen may exhibit a "Haasen and Kelley" /23/ unloading yield point which is additive to the strain-aging yield point. To eliminate this unwanted feature, Bolling $/ 24 /$ has recommended that specimens be aged under loads greater than 50 to $60 \%$ of the prestrain load.

The importance of the strain-aging under load test is that it allows the kinetics of strain-aging to be measured under conditions approaching those existing during DSA. Such an experiment thus forms a natural link between DSA and static strain-aging.

The strain-rate during aging under a constant load has been measured as a function of the aging load in an investigation $125,26 /$ of the vanadium-oxygen system. The results obtained at $363 \mathrm{~K}$ using a prestrain strain-rate of $6.7 \times 10^{-5}$ and a prestrain of $9 \%$ are shown in Fig. 1 where the fraction of the prestrain stress during aging is plotted against the average strainrate over a 35 minute aging period using double logarithmic coordinates. Note that a straight line can be passed through the data points. This implies a power law between the aging load and the average strain-rate. If this line is extrapolated back to the prestrain stress, the average strain-rate approaches that existing during 


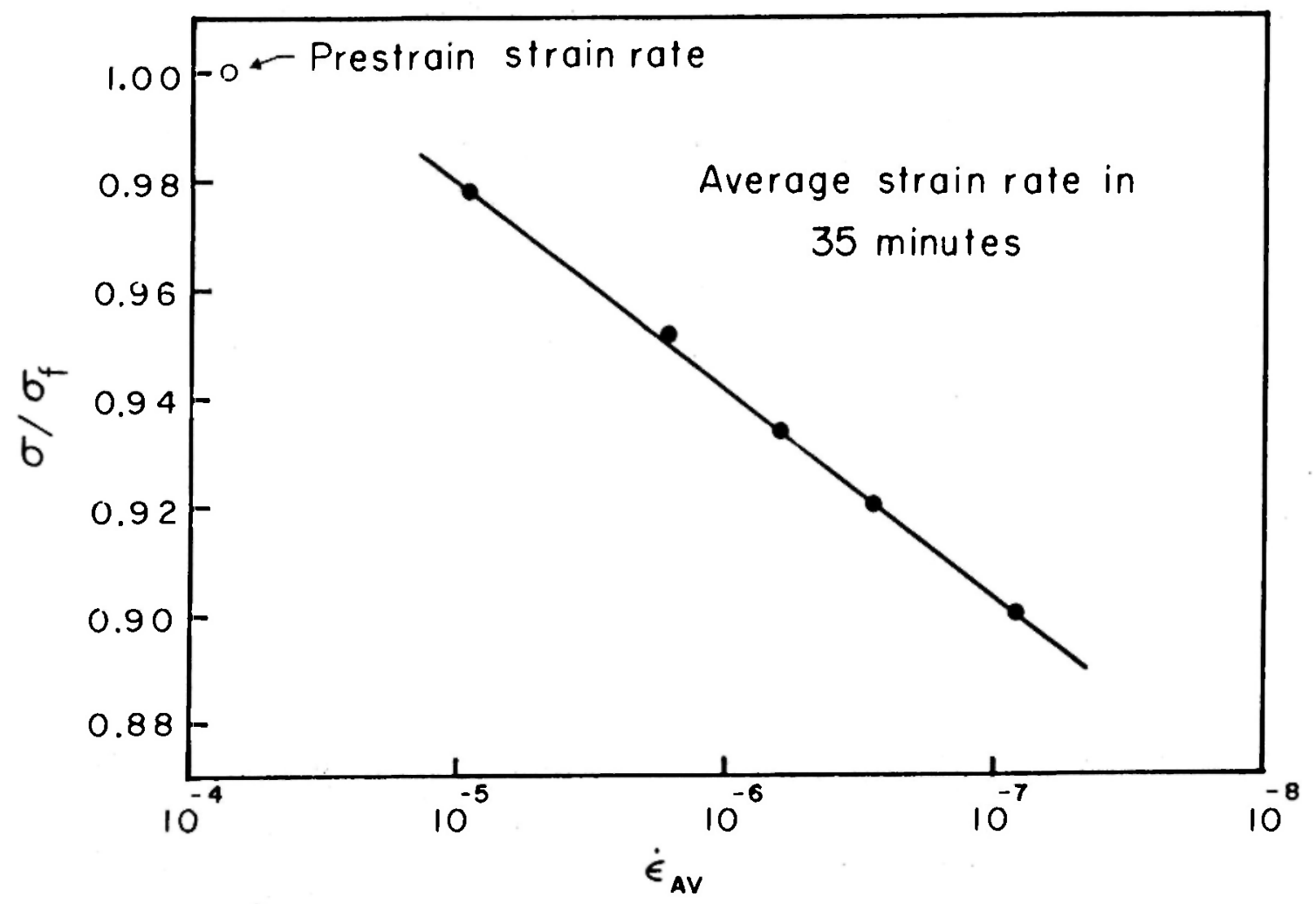

Fig. 1. The average strain rate, $\dot{\epsilon}_{\mathrm{Av}}$, for a 35 minute aging period plotted against the ratio of aging stress to prestrain flow stress, $\sigma / \sigma_{\mathrm{f}}$. Vanadium specimens containing $132 \mathrm{ppm}$ oxygen prestrained $9 \%$ at $\dot{\epsilon}=6.7 \times 10^{-5} \mathrm{~s}^{-1}$ and a temperature $353 \mathrm{~K}$. After $/ 26 /$.

the prestrain. It does not equal the latter because during the aging period there is always some decrease in the strain-rate with time which is reflected in the average. On the other hand, if the aging strain-rate were to be evaluated at the start of the aging cycle, this latter quantity should extrapolate back to the prestrain strain-rate. This initial strain-rate, however, is much more difficult to determine experimentally than the average over an aging period.

Figure 1 also shows that if the stress during aging is decreased to about $0.9 \sigma_{\mathrm{p}}$, where $\sigma_{\mathrm{p}}$ is the prestrain stress, the strain-rate during aging decreases by less than three orders of magnitude from the prestrain strain-rate. This is important because a large fraction of the significant data in the literature cites strainaging experiments in which the load was simply allowed to relax during aging. In a test of this type the power is turned off after the desired prestrain has been reached. Aging is then carried out while the specimen sits in the testing machine and the load falls back as the specimen continues to deform at a decreasing rate. This type of strain-aging has been estimated $125 /$ to occur while the specimen deforms at a strainrate between $10^{-4}$ to $10^{-7} \mathrm{~s}^{-1}$, a range of strain-rates frequently employed in slower tensile tests and faster creep tests. Thus the strain-rates during a typical aging under load experiment are not significantly different from those in slow tensile or fast creep tests in which DSA phenomena are observed.

\section{The Kinetics of the Yield Point Return When Measured Under Load}

Although in recent years the number of strain-aging studies has been limited, there have been several studies of strain-aging under stress using load relaxation during aging. Some of these papers $/ 27-30 /$ have also been concerned with aging systems involving interstitial atom solutes in bcc metals. Among these latter, the papers by Delobelle and Oytana /28/ and by Delobelle, Oytana and Varchon /27/ are significant, because in them evidence is presented showing that aging under stress tends to produce yield point return curves with kinetics corresponding closely to those observed in static strain-aging investigations. Earlier papers $/ 24$, $31-34 /$ also tend to confirm this fact. However, the later work is, on the whole, more systematic and involves more and better data as well as a more complete analysis. Thus, it is shown that in the early stages of strain-aging in the $\mathrm{Nb}-\mathrm{O}, \mathrm{Ta}-\mathrm{O}$ and $\mathrm{Fe}-\mathrm{C}-\mathrm{N}$ systems 
where the yield point return is due to Snoek ordering, the strain-aging kinetics can be characterized by the simple relaxation law

$$
\Delta \sigma_{s}=\Delta \sigma_{s_{m}}\left[1-\exp \left(-\frac{t}{\tau_{s}}\right)\right]
$$

where $\Delta \sigma_{\mathrm{s}}$ is the magnitude of the Snoek component of the yield stress, $\Delta \sigma_{s_{m}}$ is the maximum value of $\Delta \sigma_{s}, t$ is the time and $\tau_{s}$ is an experimental relaxation time that is often somewhat smaller than the Snoek relaxation time as determined with a torsion pendulum or an elastic after-effect experiment. A rationalization / $35 /$ of this difference has been made.

\section{Cottrell Strain-Aging}

Delobelle et al. $/ 27 /$ have also shown that for aging times long enough to begin to form dislocation atmospheres around a dislocation, the yield point return conforms to Cottrell-Bilby / $14 /$ kinetics with

$$
\Delta \sigma_{c} \propto t^{2 / 3}
$$

where $\Delta \sigma_{c}$ is the Cottrell component of the yield point.

\section{Comments on the Cottrell-Bilby Equation}

The Cottrell-Bilby relation

$$
\mathrm{n}=\alpha \mathrm{n}_{0}\left(\frac{\mathrm{ADt}}{\mathrm{kT}}\right)^{2 / 3}
$$

actually gives only $\mathrm{n}$, the number of solute atoms per unit length of dislocation that arrive at the dislocation within the time $t$. In this equation, $n_{0}$ is the nominal concentration of the solute (number of atoms per unit volume), $\alpha$ a constant equal to about $3, \mathrm{~A}$ the interaction energy constant, $D$ the solute atom diffusion coefficient, $t$ the time, while $k$ and $T$ have their usual significance. To apply the Cottrell-Bilby /14/ equation to the analysis of strain-aging data one needs to assume that the rise in the yield stress, $\Delta \sigma$, is proportional to $\mathrm{n}$ or that

$$
\Delta \sigma \propto \alpha \mathrm{n}_{0}\left(\frac{\mathrm{ADt}}{\mathrm{kT}}\right)^{2 / 3}
$$

Such a proportionality implies that it should be possible to obtain a linear plot between $\Delta \sigma$ and $\mathrm{t}^{2 / 3}$. For simple single atom aging systems such as an interstitial atom in a bcc metal, a proportionality between $\Delta \sigma$ and $t^{2 / 3}$ has been observed many times, as long as the aging time was relatively short.

\section{The Harper Equation}

At longer aging times a $\Delta \sigma$ versus $\mathrm{t}$ curve tends to saturate or reach a maximum value. Under these conditions, the proportionality in Eq. (22) no longer holds. If one disregards the formation of second phase precipitates at the dislocation, there are still several possible causes for a $\Delta \sigma$ versus $\mathrm{t}$ curve to approach or reach saturation. First, as assumed by Harper $/ 36 /$, the rate of flow of the solute to the dislocation may be decreased in proportion to the amount of solute already segregated. On this basis, Harper derived the equation.

$$
f=1-\exp \left[-\alpha \rho\left(\frac{A D t}{k T}\right)^{2 / 3}\right]
$$

where $f$ is the fraction of solute already segregated; i.e. $f=n \rho / n_{0}$ where $\rho$ is the dislocation density. It can be easily demonstrated that the Harper equation reduces to the Cottrell-Bilby equation at short times.

Another reason for the $\Delta \sigma$ versus $\mathrm{t}$ curve to saturate is that as the solute concentration builds up close to the dislocation, a concentration gradient forms. This concentration gradient is such as to promote a flow of solute away from the dislocation, thus opposing the drift of solute, under the strain gradient, towards the dislocation. Bullough and Newman /37-39/ have strongly supported this factor in strain-aging. On this basis, the Cottrell-Bilby and the Harper theories could be considered inadequate. However, as pointed out by Hall $/ 40 /$, the equations from the more correct theory of Bullough and Newman are complex, and difficult to compare with experiments. On the other hand, the Cottrell-Bilby and Harper equations can, in many cases, give excellent descriptions of empirical data. If one considers the Harper equation as being a good phenomenological tool, it can be very useful. This is supported by Hartley /41/, who states, "...it is generally found that Harper's modification of the Cottrell-Bilby relationship is a good fit for most experimental measurements of the rate of removal of interstitial solute from solution."

Bolling $/ 24 /$, who made an extensive strain-aging study of the 70-30 alpha brass system, was one of the first to use the Harper equation to describe strainaging phenomena. His experimental technique involved 
strain-aging under load using load relaxation. Because of the high solute concentration of his brass, Bolling redefined $f$, the fraction of solute segregated, as

$$
\mathrm{f}=\mathrm{n} / \mathrm{n}_{\mathrm{nt}}
$$

where $\mathrm{n}$ represents the number of atoms segregated and $n_{m}$ the maximum number that can segregate. This leads to

$$
f=1-\exp \left[-\alpha \frac{n_{0}}{n_{m}}\left(\frac{A D t}{k T}\right)^{2 / 3}\right]
$$

In order to apply this relationship to his strain-aging data, Bolling had to assume that

$$
\Delta \sigma \propto \mathrm{n}, \quad \Delta \sigma_{\mathrm{m}} \propto \mathrm{n}_{\mathrm{m}}
$$

and that

$$
\mathrm{f}=\Delta \sigma / \Delta \sigma_{\mathrm{m}}
$$

so that

$$
\Delta \sigma=\Delta \sigma_{\mathrm{m}}\left\langle 1-\exp \left[-\mathrm{K}\left(\frac{\mathrm{Dt}}{\mathrm{T}}\right)^{2 / 3}\right]\right\rangle
$$

where

$$
\mathrm{K}=\alpha \frac{\mathrm{n}_{0}}{\mathrm{n}_{\mathrm{m}}} \cdot\left(\frac{\mathrm{A}}{\mathrm{k}}\right)^{2 / 3}
$$

Bolling was able to obtain reasonable straight lines when $(1-f)$ was plotted against $t^{2 / 3}$ for his fcc substitutional alloy data.

\section{An Alternate Form for the Bolling-Harper Equation for an Interstitial Solute}

The Bolling modification of the Harper equation can also be written

$$
\Delta \sigma=\Delta \sigma_{\max }\left\langle 1-\exp \left[-\frac{\mathrm{K}_{1}}{\mathrm{~T}^{2 / 3}}\left(\frac{\mathrm{t}}{\tau_{\sigma}}\right)^{2 / 3}\right]\right\rangle
$$

where

$$
\frac{1}{\tau_{\sigma}}=\frac{36 \mathrm{D}}{\mathrm{a}^{2}}=\frac{36 \mathrm{D}_{0} \exp -\mathrm{Q} / \mathrm{kT}}{\mathrm{a}^{2}}
$$

a is the lattice parameter of the bcc metal, D is the diffusion coefficient for an interstitial solute in this metal, $D_{0}$ the corresponding frequency factor, $Q$ the diffusion activation energy of the interstitial solute and $K_{1}=\left(a^{2} / 36\right)^{2 / 3} \mathrm{~K}$.
Equation (30) is given because of its similarity to the phenomonological equation used by Delobelle et al. /27/ to fit in the range of Cottrell aging both their $\mathrm{Nb}-\mathrm{O}$ data and the $\mathrm{Fe}-\mathrm{C}$ data of Rosinger $/ 30 \%$ This equation is

$$
\Delta \sigma_{\mathrm{c}}=\Delta \sigma_{\mathrm{c}_{\mathrm{m}}}\left\langle 1-\exp \left[-\left(\frac{\mathrm{t}}{\tau_{\mathrm{c}}}\right)^{2 / 3}\right]\right\rangle
$$

where $\tau_{\mathrm{c}}$ is a relaxation time with an activation energy equal to that for the diffusion of the interstitial solute. Thus, we may write

$$
\frac{1}{\tau_{\mathrm{c}}}=\frac{1}{\tau_{\mathrm{c}_{0}}} \exp -(\mathrm{Q} / \mathrm{kT})
$$

where $Q$ is the activation energy for solute diffusion. The parameter $1 / \tau_{\mathbf{c}_{0}}$, however, does not equal $1 / \tau_{\sigma_{0}}$ as determined in an internal friction elastic after-effect experiment. In fact, $1 / \tau_{\mathrm{c}_{0}}$ is probably larger than $1 / \tau_{\sigma_{0}}$ by a factor of the order of $10^{3}$ or more $/ 27 /$. By comparing Eqs. (30) and (32), it is apparent that

$$
1 / \tau_{\mathrm{c}}=\frac{\mathrm{K}_{1}^{3 / 2}}{\mathrm{~T}} \cdot \frac{1}{\tau_{\sigma}}
$$

In the experimental temperature range where strainaging data are normally collected, the variation of $T$ is small compared to the variation with $\mathrm{T}$ of the parameters $1 / \tau$ and $1 / \tau_{\sigma}$ so that to a reasonable approximation we may write

$$
1 / \tau_{\varepsilon}=\mathrm{K}_{2} \frac{1}{\tau_{\sigma}}
$$

where $\mathrm{K}_{2}=\mathrm{K}_{1}^{3 / 2} / \mathrm{T}$ is considered a constant.

\section{Additional Support for the Delobelle and Oytana Conclusions}

In addition to the $\mathrm{Nb}-\mathrm{O}$ and $\mathrm{Ta}-\mathrm{O}$ systems, strainaging under stress has been studied in the $\mathrm{V}-\mathrm{O}$ system $125,26 /$, where aging was carried out under an effectively constant load and only the Snoek strain-aging region was investigated in detail. It was confirmed that Eq. (19) fits the experimental data.

The Bolling /24/ data for a substitutional fcc alloy system (70-30 alpha brass) has already been considered. Here strain-aging conforms to Cottrell aging and Bolling was able to fit a modified Harper equation, Eq. (28), to his data. 


\section{A CONCLUSION FROM STRAIN AGING STUDIES}

In a typical strain aging experiment a specimen is prestrained, aged and then reloaded. The increase in flow stress due to aging is then measured as the difference between the flow stress just after reloading and that at the end of prestraining, i.e. $\Delta \sigma=\sigma_{R}-\sigma_{p}$ where $\Delta \sigma$ is the increase in stress, $\sigma_{\mathrm{R}}$ the reloading flow stress and $\sigma_{\mathrm{p}}$ the prestrain flow stress. Thus, empirically the reloading stress is the sum of a prestrain stress and a strain aging stress or $\sigma_{R}=\sigma_{p}+\Delta \sigma$. This strongly suggests that during DSA the total flow stress might be considered as the sum of the strain aging stress $\sigma_{\text {DSA }}$ and the flow stress that should exist in the absence of strain aging or

$$
\sigma_{\mathrm{t}}=\sigma_{\text {DSA }}+\sigma
$$

where $\sigma_{\mathrm{t}}$ is the total stress, $\sigma_{\mathrm{DSA}}$ is the strain aging part of the stress, $\sigma$ is the sum of $\sigma^{*}$ the effective stress and $\sigma_{E}$, the internal stress.

\section{A NEW THEORY OF DYNAMIC STRAIN-AGING}

A rationalization of the effects of DSA on stressstrain behavior will now be attempted. This is outlined below.

1. It is assumed that the total flow stress $\sigma_{\mathrm{t}}$ in a temperature region of DSA consists of two separable parts. The first, the stress $\sigma$ which would exist in the absence of dynamic strain-aging and the other the stress, $\sigma_{\mathrm{DSA}}$, due to dynamic strain-aging. The separation of the stress into components can be rationalized as follows. The theory of thermally activated plastic flow suggests that in the absence of DSA deformation at a fixed temperature, strain rate and mobile dislocation density (strain) requires a flow stress which is the sum of the effective stress $\sigma^{*}$ and a long range internal stress $\sigma_{\mathrm{E}}$. During DSA, dislocations are aged as they wait for thermal activation. Thus, for a dislocation to advance past an obstacle it must simultaneously free itself from the obstacle and escape from an atmosphere. The stress to move the dislocations should therefore be the sum of $\sigma_{\mathrm{DSA}}, \sigma^{*}$ and the internal stress $\sigma_{\mathrm{E}}$.

2. In a bcc-interstitial atom system the DSA stress will be considered to consist of two parts; one due to Snoek ordering and the other to the formation of Cottrell atmospheres. This is consistent with yield point return curves observed in this type of strainaging system. The Snoek component of the dynamic strain-aging part of the stress will be assumed to be given by Eq. (19) and the Cottrell component by Eq. (32). Where $t$ in both Eqs. (19) and (32) is taken to be $t_{w}$ the Sleeswyk /13/ arrest time that a dislocation experiences as it waits for thermal activation.

3. Following McCormick and van den Beukel it is assumed that the arrest time $t_{w}$ is related to the strain-rate by the Orowan equation $\dot{\epsilon}=\phi \rho_{\mathrm{m}} \mathrm{b} \overline{\mathrm{v}}$ where $\phi$ is a Schmid orientation factor, $\rho_{\mathrm{m}}$ the mobile dislocation density, $b$ the Burgers vector and $\bar{v}$ the mean dislocation velocity given by $\bar{v}=\mathrm{L} / \mathrm{t}_{\mathrm{w}}$ where $\mathrm{L}$ is the effective mean distance between obstacles to the motion of the dislocations.

4. It will also be assumed that the effective part of the DSA independent stress component $\sigma^{*}$ can be described by the power law

$$
\sigma^{*}=\sigma_{0}^{*}\left(\dot{\epsilon} / \dot{\epsilon}_{0}\right)^{\mathrm{n}}
$$

where $\epsilon$ is the strain-rate, $\sigma_{0}^{*}$ and $\dot{\epsilon}_{0}$ are constants and $\mathrm{n}$ the strain-rate sensitivity. It is further assumed that $\mathrm{n}$ is given by $\mathrm{n}=\mathrm{kT} / \mathrm{H}^{0}$ where $\mathrm{k}$ is Boltzmann's constant and $\mathrm{H}^{\circ}$ a constant. Equation (37) can now be written

$$
\sigma^{*}=\sigma_{0}^{*}\left(\dot{\epsilon} / \dot{\epsilon_{0}}\right)^{\mathrm{kT} / \mathrm{H}^{0}}
$$

This latter equation gives an excellent description of much of the data in the literature dealing with relatively pure metals. By setting $\mathrm{T}=0$ it can be deduced that $\sigma_{0}^{*}$ represents the effective stress at this temperature. On the other hand, $\dot{\varepsilon}_{0}$ is the strain-rate that makes $\sigma^{*}=\sigma_{\jmath}^{*}$ at any temperature. For data obtained at constant strain-rate, Eq. (38) leads to a linear relation between $\ln \sigma^{*}$ and $T$, i.e.,

$$
\ln \sigma^{*}=\ln \sigma_{\mathrm{J}}^{*}+\mathrm{BT}
$$

where at constant strain-rate, $\mathrm{B}=\mathrm{k} / \mathrm{H}^{0} \ln \left(\dot{\epsilon}_{0} / \dot{\epsilon}\right)$ is a constant. To verify that Eq. (39) describes a large amount of the available single crystal data one need only examine a review paper by Ahlers $/ 42 /$.

The power law of Eq. (38) also conforms to an activation enthalpy in the thermally activated strainrate equation (Eq. 16)

$$
\mathbf{H}=\mathrm{H}^{0} \ln \frac{\sigma_{\mathrm{a}}^{*}}{\sigma^{*}}
$$

where $\mathrm{H}$ is the activation enthalpy, $\mathrm{H}^{0}$ a constant, $\sigma^{*}$ the effective stress and $\sigma_{0}^{*}$ the effective stress at $0 \mathrm{~K}$.

The power law in Eq. (38) also has considerable theoretical justification. Hartley has demonstrated 
that this power law results if the interaction stress between a moving and a forest dislocation is taken into account in the dislocation intersection mechanism. Hartley also concludes that such a power law should be expected whenever the interaction stresses between segments of a mobile dislocation and an obstacle can be assumed to vary inversely to the distance between them.

In addition to Hartley's derivation of the power law relation for dislocation intersections there are two other specific mechanisms for which it has been derived. These are Seeger's model /43/ for overcoming the Peierl's stress, and the thermally activated cross-slip mechanism of Schoeck and Seeger /44/.

It is necessary to mention that the power law of Eq. (38) requires the use of $\sigma^{*}$. This means that the applied stress, $\sigma$, can only be substituted in Eq. (38) for $\sigma^{*}$ if the data were obtained under conditions where the applied stress nearly equals the effective stress, $\sigma^{*}$. Normally one cannot expect experimental applied stress data to conform well to Eq. (38) if a large long range or internal stress component $\sigma_{\mathrm{E}}$ exists. Furthermore, the correlation should also fail if there is a strong DSA component of the flow stress. However, in spite of these caveats, there is an abundance of empirical evidence in support of Eq. (39) (and thus Eq. 38) that was obtained when the measured stress was effectively $\sigma^{*}$. This includes the molybdenum single crystal data of Prekel, Lawley and Conrad /45/, $\mathrm{Zr}-\mathrm{O}$ data $/ 21 /, \mathrm{Nb}-\mathrm{O}$ data /46/ and $\mathrm{Cu}-3.1 \mathrm{Sn} / 60 /$ data. Noteworthy in this regard is the previously mentioned paper by Ahlers $/ 42 /$ in which he reviewed the single crystal literature and found many examples of good linear relations between $\ln \sigma$ and $T$ in f.c.c., b.c.c. and h.c.p. metals.

In summary, the power law in Eq. (38) requires the use of the effective stress $\sigma^{*}$. The acquisition of data at temperatures too low for dynamic strain aging to occur will eliminate $\sigma_{\mathrm{DSA}}$ from the observed stress. The applied stress will then only approach the effective stress $\sigma^{*}$ if undeformed high purity metals of large grain size (or single crystals) where $\sigma_{\mathrm{E}}$ is small are used. If $\sigma_{\mathrm{E}}$ is finite one must evaluate $\sigma_{\mathrm{E}}$ before $\sigma^{*}$ can be determined since only the applied stress is found directly, and $\sigma^{*}=\sigma-\sigma_{\mathrm{E}}$.

The evaluation of $\sigma_{\mathrm{E}}$ has always proved to be difficult. However, a basic part of the present model is a technique for evaluating $\sigma_{\mathrm{E}}$. The details of this procedure are given in Ref. $/ 46 /$. In brief, one needs (a) to assume Eq. (38), (b) to have available flow stress and strain rate sensitivity data measured at low enough temperatures so that DSA does not occur and (c) to have a knowledge of the temperature dependence of the elastic modulus.

\section{THE RELATION OF THE PRESENT MODEL TO EARLIER DISLOCATION DYNAMICS THEORY}

The present flow stress model is important because it is both simple and scientifically acceptable. For example it does not require that the pre-exponential term, $\dot{\epsilon}_{0}$, in the thermally activated strain rate equation $\epsilon=\dot{\epsilon}_{0} \exp -(\mathrm{H} / \mathrm{kT})$ be strongly temperature or strain rate dependent in order to rationalize data when DSA is a factor.

The model, however, differs significantly from the conventional approach to metal plasticity used in dislocation dynamics. To explain why there is this difference it is merely necessary to examine dislocation dynamics history. The dislocation intersection mechanism furnishes an excellent subject for this purpose.

In 1952 Cottrell /47/ proposed that the activation enthalpy for the dislocation intersection mechanism might have the form

$$
\mathrm{H}=\alpha \mu \mathrm{b}^{3}-\tau \mathrm{b}^{2} 1
$$

where $\alpha$ is a constant, $\mathrm{b}$ the Burgers vector, $\mu$ the shear modulus, 1 the distance between forest dislocations and $\tau$ the applied stress. The term $\alpha \mu \mathrm{b}^{3}$ in this equation was identified with the energy to form the jogs resulting from an intersection while the second term, $\tau \mathrm{b}^{2} l$, represented the work done by the stress during the intersection. Note that this early equation did not consider the interaction stress between moving and forest dislocation nor the possibility that this stress should affect the activation enthalpy. In summary, Cottrell's model simply assumed that a moving dislocation moves up to a forest dislocation until their cores come in contact, and that a movement through a distance of about a Burgers vector is required to complete an intersection. The action of the applied stress was only considered to occur over this distance. This can no longer be considered a realistic model.

Cottrell's equation was later adopted by Seeger /48/ in 1957 who substituted $\tau^{*}$, the effective stress for the applied stress, $\tau$, so that the activation enthalpy became

$$
\mathrm{H}=\mathrm{H}_{0}-\mathrm{v} \tau^{*}
$$

where $v$ is the activation volume $\left(b^{2} l\right)$ and $\tau^{*}$ was assumed to be given by 


$$
\tau^{*}=\tau-\tau_{\mu}
$$

with $\tau_{\mu}$ the long range internal stress. Seeger /48/ then made the additional assumption that $\tau_{\mu}$ could be evaluated at the plateau of a plot of the flow stress versus temperature by setting $\tau_{\mu}$ equal to $\tau$ at the plateau. In 1957 DSA was not well understood and Seeger's assumption appeared reasonable. However, at this time it is well established that the plateau is associated with DSA so that $\tau_{\mu}$ does not necessarily equal $\tau$ at the plateau.

The principal difficulty with Seeger's method of evaluating $\tau_{\mu}$ is that it requires $\tau^{*}$ to go to zero at the flow stress plateau. Its effect on the deduced numerical values of $\tau_{\mu}$, at temperatures, below the plateau, is in most cases small. This assumption, however, places a serious limitation on the mathematical form of the activation enthalpy relation and it favors Eq. (42) over Eq. (40). This, in our opinion, is why Eq. (42) has been so widely accepted in spite of the fact that, almost from the start, both experimental evidence and theoretical reasoning strongly supported Eq. (40). Furthermore, it was not long after the introduction of Eq. (42) that serious problems began to appear with its use. Thus, in 1961 from a study of thermally activated glide in magnesium crystals conducted between $4.2 \mathrm{~K}$ and $420 \mathrm{~K}$, Conrad, Hays, Schoeck and Wiedersich /49/ concluded that the rate controlling mechanism at low temperatures was the intersection of dislocations and that Seeger's (1957) simple model must be modified to include an effect of stress on the activation volume, a parameter which, according to the original theory, should be constant.

This stress dependence of the activation volume, $v$, is, moreover, not weak. In fact when the applied stress, $\tau$, happens to nearly equal the effective stress, $\tau^{*}$, the experimentally determined activation volumes usually vary approximately as $1 / \tau$. This being the case the product $\mathrm{v} \tau$ or $\left(\mathrm{v} \tau^{*}\right)$ should be approximately constant so that the stress dependence of the activation enthalpy has to appear in $\mathrm{H}_{0}$, the first term on the right hand side of Eq. (42). This means that both constants in the Cottrell (Seeger) relation $\mathrm{H}_{0}$ and $v$ have to be treated as variables in order to actually use Eq. (42).

In summary Eq. (42) is awkward, it ignores the interaction stresses between moving and forest dislocations and it requires the effective stress, $\sigma^{*}$, to go to zero at the flow stress plateau. On the other hand, Hartley has demonstrated that if the interaction stress is taken into account Eqs. (38) and (40) follow directly. These equations do not require $\sigma^{*}$ to equal zero at the flow stress plateau. As a result we feel that there is ample justification for the use of Eq. (38).

\section{The Temperature Dependence of the Dynamic Strain-Aging Components of the Stress}

Assuming that $t$ equals the waiting time $t_{w}$, and that $t_{w}$ is constant (i.e. $\epsilon$ and $\dot{\epsilon}$ are constants) Eqs. (19) and (33) will give Snoek and Cottrell components of the flow stress that grow with increasing temperature and reach maximum values in the dynamic strainaging temperature range as illustrated in Fig. 2. According to these equations once these components attain their maximum values, they do not decrease in magnitude as the temperature is raised above those normally associated with DSA. Such behavior is not consistent with published plots of the flow stress versus temperature, which show that above the yield stress plateau the total flow stress decreases progressively with temperature.

It is possible, however, to allow for a dynamic recovery dependence of the dynamic strain-aging components if $\sigma_{s_{m}}$ and $\sigma_{c_{m}}$ which determine the maximum amplitudes of the Snoek and Cottrell stresses are taken as temperature dependent. For convenience, it is assumed that this temperature dependence is given by

$$
\begin{aligned}
& \sigma_{s_{m}}=\sigma_{s_{m}}^{0} \exp [-\alpha(T-300)] \\
& \sigma_{c_{m}}=\sigma_{c_{m}}^{0} \exp [-\alpha(T-300)]
\end{aligned}
$$

where $\alpha$ is a dynamic recovery constant and $\sigma_{s_{m}}^{0}$ and $\sigma_{c_{m}}^{0}$ are parameters that determine the relative magnitude of the two stresses normalized to $300 \mathrm{~K}$.

If the variation of the dynamic strain-aging stress with temperature shown in Fig. 2 is recomputed with the aid of Eqs. (44) and using a value for $\alpha$ that gives these components the same temperature dependence as $\sigma^{*}$, one obtains the results shown in Fig. 3 .

The total stress may now be written assuming the power law is applicable,

$$
\begin{aligned}
& \sigma_{\mathrm{t}}=\sigma_{\mathrm{E}}+\sigma_{j}^{*}\left(\dot{\epsilon} / \dot{\epsilon}_{0}\right)^{\mathrm{kT} / \mathrm{H}^{0}}+ \\
& +\left(\sigma_{j_{\mathrm{m}}}^{0}\left\langle 1-\exp \left[-\left(\frac{\mathrm{t}_{\mathrm{w}}}{\tau_{\mathrm{sn}}}\right)\right]\right\rangle+\right. \\
& \left.+\sigma_{\mathrm{c}_{m}}^{0}\left\langle 1-\exp \left[-\left(\frac{\mathrm{t}_{\mathrm{w}}}{\mathrm{t}_{\mathrm{cot}}}\right)^{2 / 3}\right]\right\rangle\right) \times \\
& \times(\exp [-\alpha(\mathrm{T}-300)]\rangle
\end{aligned}
$$




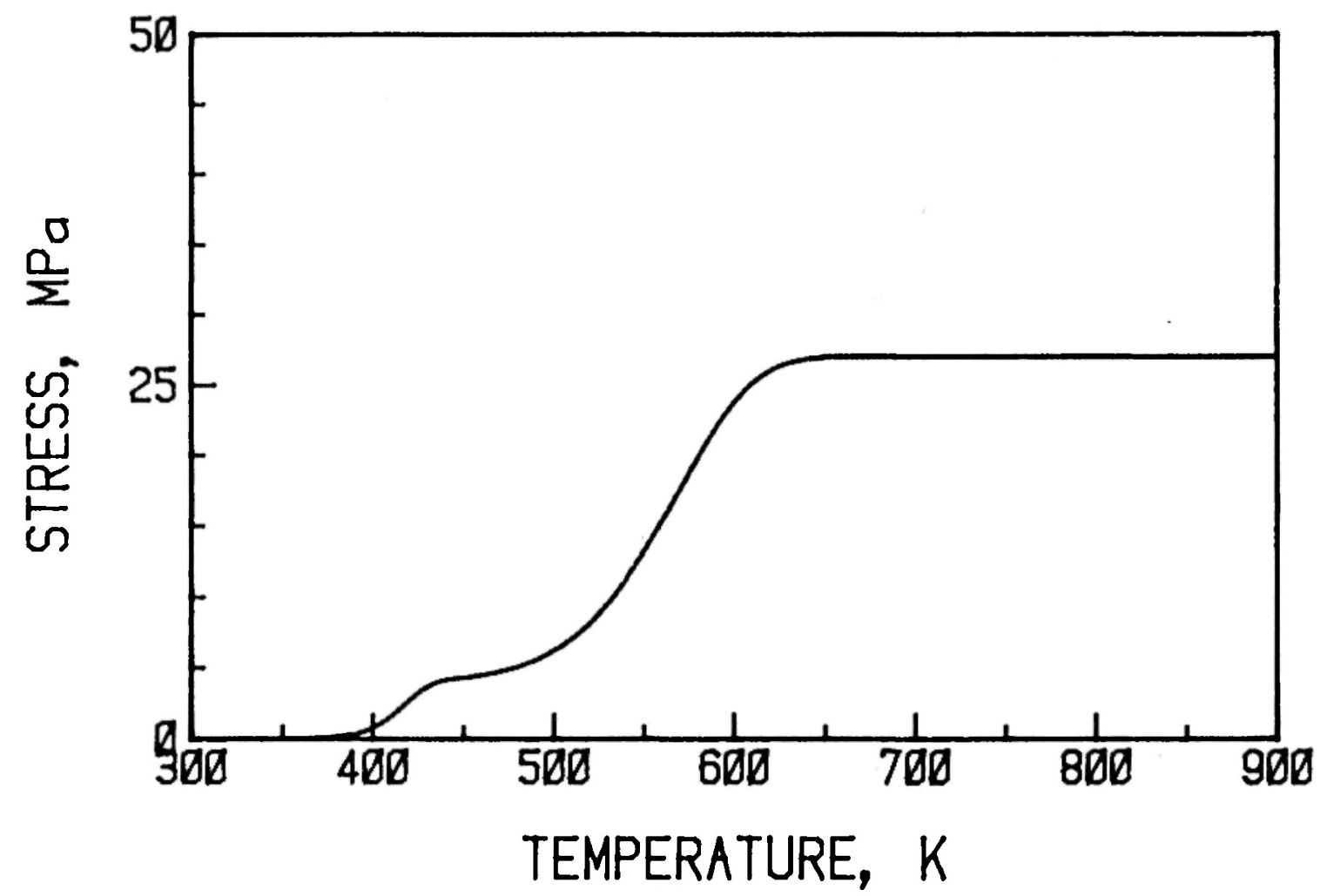

Fig. 2. The variation of the DSA stress with temperature under the condition of a fixed waiting time $t_{\mathrm{m}}$ :

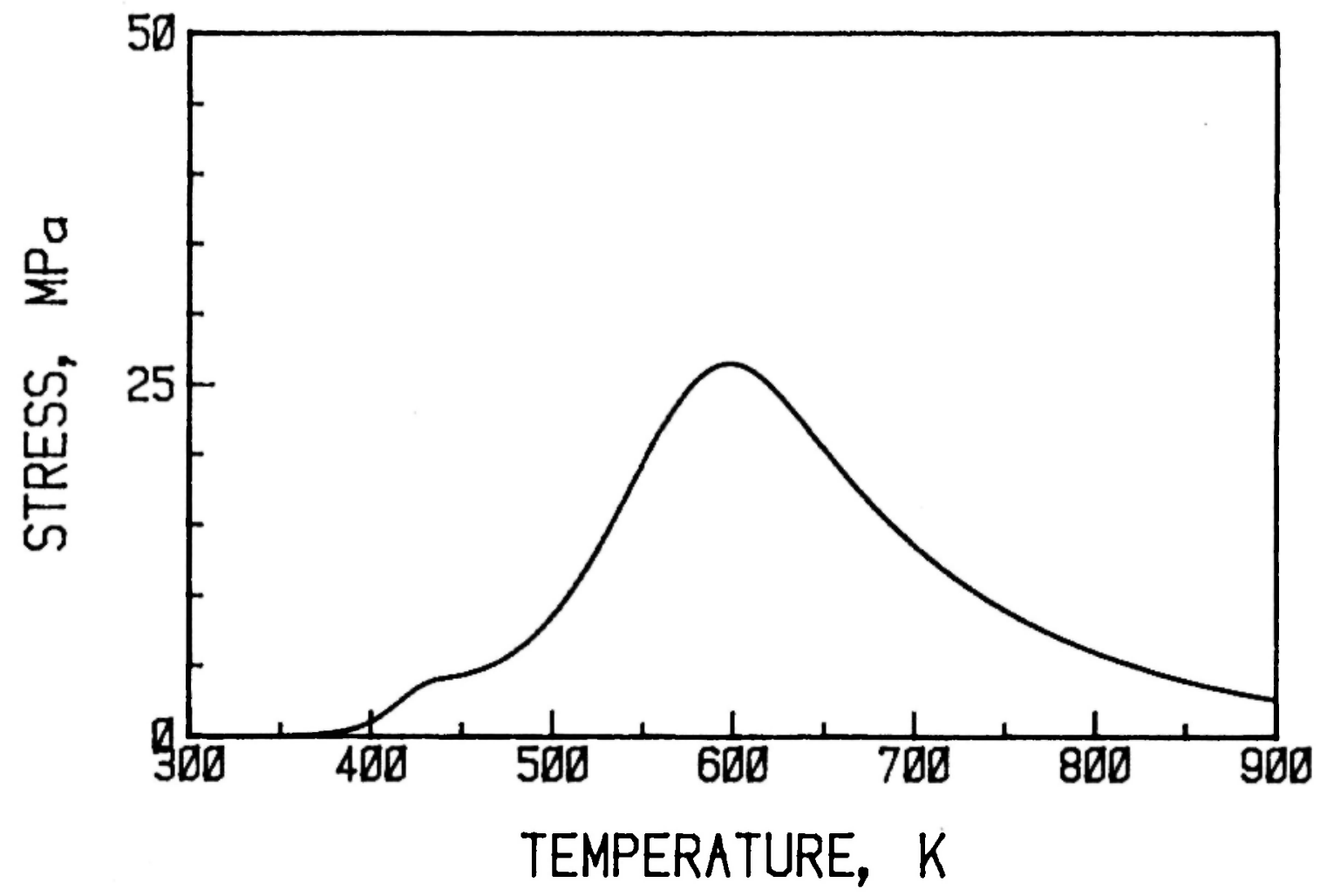

Fig. 3. The variation of the DSA stress with temperature assuming a fixed $t_{w}$ and that the Snoek and Cottrell maximum stress amplitudes are subject to dynamic recovery. 


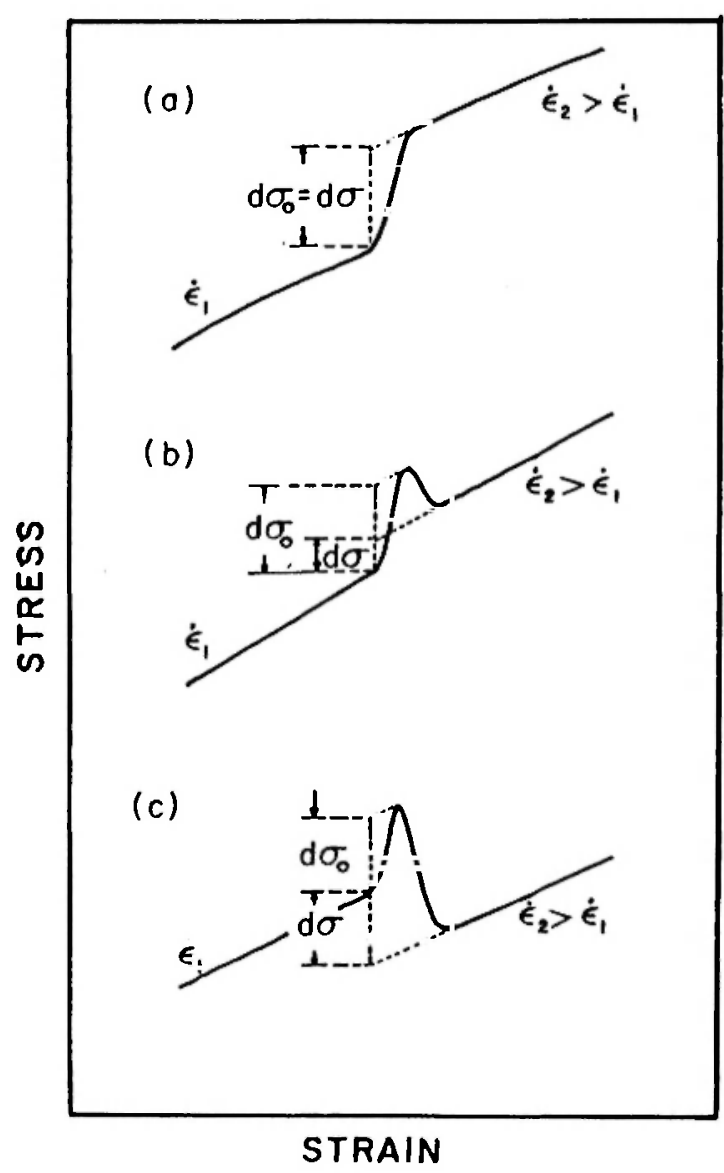

Fig. 4. Illustrating some of the possible effects of a change in strain-rate on the shape of the stress-strain curve. (a) The case where there is no DSA, (b) where DSA occurs and produces a flow stress transient and (c) where DSA is strong enough to cause a negative strain-rate sensitivity.

\section{The Strain-Rate Sensitivity}

The strain-rate sensitivity can be expressed in several ways. The two most used parameters are

$$
\mathrm{n}=\frac{\mathrm{d} \ln \sigma}{\mathrm{d} \ln \dot{\epsilon}} \quad \text { and } \quad \mathrm{s}=\frac{\mathrm{d} \sigma}{\mathrm{d} \ln \dot{\epsilon}}
$$

The first, $\mathrm{n}$, has the advantage that it is a dimensionless parameter. On the other hand, in the field of DSA the second parameter, $s$, is more generally used. Also $s$ is closely related to the activation volume $v$; i.e., $\mathrm{v}=\mathrm{kT} / \mathrm{s}$.

\section{EMPIRICAL OBSERVATIONS CONCERNING THE STRAIN RATE SENSITIVITY}

When there is no DSA, an increase in strain-rate normally increases the overall level of the stress-strain curve as shown schematically in Fig. 4a. However, when DSA begins to influence stress-strain behavior, flow stress transients like those in Figs. $4 \mathrm{~b}$ and $4 \mathrm{c}$ are usually observed. These transients correspond to an initial rapid rise in stress of magnitude, $\mathrm{d} \sigma_{0}$. The stress level then drops back and the stress-strain curve may continue at a level either somewhat higher or somewhat lower than that of the stress-strain curve before the increase in the strain-rate. The resulting effective quasi-steady state change in the flow stress is designated by $\mathrm{d} \sigma$ and is normally evaluated by extrapolation as indicated in Figs. $4 \mathrm{~b}$ and $4 \mathrm{c}$.

According to van den Brink et al. $/ 18 /$, the initial rapidly rising flow stress increment, $\mathrm{d} \sigma_{0}$, is the flow stress change expected in the absence of strain-aging. On the other hand, $\mathrm{d} \sigma$ represents the change in flow stress when the effects of dynamic strain-aging are also taken into account. An increase in strain-rate has the effect of decreasing the waiting time from its value $t_{w_{1}}$ at $\dot{\epsilon}_{1}$ to $t_{w_{2}}$ at $\dot{\epsilon}_{2}$. This in turn lowers the degree of strain-aging by decreasing the solute concentration at the dislocations. However, as van den Brink et al. /18/ point out, when the strain-rate is increased, the resulting decrease in solute concentration at the dislocation cannot occur instantly but requires a finite time interval of the order of $t_{w_{2}}$ in order to be accomplished. This leads to the observed flow stress transients.

Finally, it should be noted that due to dynamic strain-aging, d $\sigma$ may become negative as suggested in Fig. 4c. This, by Eq. (46), signifies a negative strainrate sensitivity. Negative strain-rate sensitivities do occur and it has been well documented that unstable plastic flow, as evidenced by serrations on a stressstrain curve, occur when the strain-rate sensitivity becomes sufficiently negative $/ 18,50-54 /$.

Because of its more general acceptance, the s parameters will be used in this presentation. To obtain an expression for this parameter one needs only differentiate Eq. (45) with respect to $\ln \dot{\epsilon}$. Assuming $\mathrm{t}_{\mathrm{w}}=\phi \rho_{\mathrm{m}} \mathrm{bL} / \dot{\epsilon}$ and $\phi \rho_{\mathrm{m}} \mathrm{bL}$ can be considered constant at a fixed strain, this leads to

$$
\begin{aligned}
& \frac{\mathrm{d} \sigma_{\mathrm{t}}}{\mathrm{d} \ln \dot{\epsilon}}=\frac{\mathrm{kT}}{\mathrm{H}_{0}} \sigma_{0}^{*}\left(\frac{\dot{\epsilon}}{\dot{\epsilon}_{0}}\right)^{\mathrm{kT} / \mathrm{H}_{0}}- \\
& -\left\langle\sigma_{\mathrm{s}_{\mathrm{m}}}^{0}\left(\frac{\mathrm{t}_{\mathrm{w}}}{\tau_{\mathrm{sn}}}\right) \times \exp \left(-\frac{\mathrm{t}_{\mathrm{w}}}{\tau_{\mathrm{sn}}} ;+\frac{2}{3} \sigma_{\mathrm{c}_{\mathrm{m}}}^{0} \times\right.\right. \\
& \left.\times\left(\frac{\mathrm{t}_{\mathrm{w}}}{\tau_{\cot }}\right)^{2 / 3} \times \exp \left[-\left(\frac{\mathrm{t}_{\mathrm{w}}}{\tau_{\mathrm{cot}}}\right)^{2 / 3}\right]\right\rangle \times \\
& \times\langle\exp [-\alpha(\mathrm{T}-300)]\rangle
\end{aligned}
$$


Note that the last term on the right hand side of Eq. (47), corresponding to the DSA stress component, is negative.

\section{Test of the Theory Using the Niobium-Oxygen Data} of Fries et al. $\quad$ 155, 56/

In two companion papers, Fries, Houssin, Cizeron and Lacombe /55/ and Fries, Cizeron and Lacombe 156/ published mechanical properties data for niobium of several purities, covering the temperature range from $20 \mathrm{~K}$ to $300 \mathrm{~K}$ in one paper, and $293 \mathrm{~K}$ to $1123 \mathrm{~K}$ in the other. Their commercial purity niobium data will be used to test the present theory. This material contained the highest oxygen level and accordingly showed the largest effects due to DSA. The variation of the flow stress (at 2\% strain) with temperature was reported for their data between $20 \mathrm{~K}$ and $300 \mathrm{~K}$ in their second paper $155 /$. The stress at $2 \%$ strain was chosen by Fries et al. in order to exceed the inhomogeneous deformation associated with yield points in some of their specimens. On the other hand in their first paper dealing with data obtained, above $293 \mathrm{~K}$, the $0.2 \%$ yield stress was reported $/ 56 /$.

It will now be shown that the data of Fries et al. can be fitted by the flow stress-temperature relation in Eq. (45) as well as by the strain-rate sensitivity equation, Eq. (47). However, the parameters in Eq. (45) need to be evaluated. To obtain those parameters involved in the non-strain aging part of the stress /46/ one uses data plots showing the temperature dependence of both the total flow stress and the strain rate sensitivity obtained at temperatures low enough so that DSA was not a factor. Examples from the data of Fries $e t$ al. are given in Figs. 5 and 6. From these data one obtains $\sigma_{0}$ the flow stress at $0 \mathrm{~K}$, the temperature $T_{m}$ of the strain rate sensitivity peak, and $S_{m}$ the strain rate sensitivity at $\mathrm{T}_{\mathrm{m}}$. Assuming that $\sigma=\sigma^{*}+$ $\sigma_{\mathrm{E}}$ where $\sigma$ is the measured flow stress, $\sigma^{*}$ the effective stress and $\sigma_{\mathrm{E}}$ the internal stress, and that $\sigma_{\mathrm{E}}=\sigma_{\mathrm{E}_{0}}$ $\left(\mathrm{E} / \mathrm{E}_{0}\right)$ where $\sigma_{\mathrm{E}}$ and $\sigma_{\mathrm{E}_{0}}$, and $\mathrm{E}$ and $\mathrm{E}_{0}$ are the internal stresses and elastic moduli at temperatures $\mathrm{T}$ and $0 \mathrm{~K}$ respectively, it can be easily shown $/ 46 /$ that

$$
\sigma_{\mathrm{E}_{0}}=\frac{\sigma_{0}-\mathrm{e} \sigma_{\mathrm{n} 1}}{\left(1-\mathrm{e} \frac{\mathrm{E}_{\mathrm{m} \mathrm{m}}}{\mathrm{E}_{0}}\right)}
$$

where $\sigma_{m}$ is the flow stress at $T_{m}$ and $e$ is the base of the system of natural logarithms. With Eq. /48/ it is possible to calculate the internal stress at $0 \mathrm{~K}$ if the temperature dependence of the modulus is known.

It can then be shown that at $T_{m}$ the following equations hold

$$
\begin{aligned}
& \sigma_{\mathrm{m}}^{*}=\sigma_{0}^{*} / \mathrm{e} \\
& \mathrm{H}_{0}=\frac{\mathrm{kT}_{\mathrm{m}} \sigma_{\mathrm{m}}^{*}}{\mathrm{~S}_{\mathrm{m}}} \\
& \dot{\epsilon}_{\mathrm{o}}=\dot{\epsilon} \exp \frac{\sigma_{\mathrm{m}}^{*}}{\mathrm{~S}_{\mathrm{m}}}
\end{aligned}
$$

The data of Fries et al. correspond to $S_{m}=17 \mathrm{MPa}$, $\mathrm{T}_{\mathrm{m}}=125.0 \mathrm{~K}$ and $\sigma_{\mathrm{m}}=510 \mathrm{MPa}$. Also, as pointed out by these authors, the modulus of niobium can be assumed constant with temperature. With this assumption and the above values for $S_{m}, T_{m}$ and $\sigma_{m}$, the values of $\sigma_{0}, \sigma_{0}^{*}, \mathrm{H}_{0}$ and $\dot{\epsilon}_{0}$ given in Table 1 were computed using Eqs. (49) to (51). It will be noted that Table 1 is given in two parts. Part (a) corresponds

TABLE 1. Power Law Parameters

$\begin{array}{ll}\text { (a) } & \text { (b) } \\ \text { (0 to } 300 \mathrm{~K}) & (300 \text { to } 900 \mathrm{~K}) \\ \epsilon=1.1 \times 10^{-3} \mathrm{~s}^{-1} & \dot{\epsilon}=1.1 \times 10^{-3} \mathrm{~s}^{-1} \\ \epsilon_{0}=2.14 \times 10^{7} \mathrm{~s}^{-1} & \dot{\epsilon}_{0}=2.14 \times 10^{7} \mathrm{~s}^{-1} \\ H_{0}=2.48 \times 10^{4} \mathrm{~J} / \mathrm{mole} & H_{0}=2.48 \times 10^{4} \mathrm{~J} / \mathrm{mole} \\ \sigma_{0}=1200 \mathrm{MPa} & \sigma_{0}=1183 \mathrm{MPa} \\ \sigma_{J}^{*}=1093 \mathrm{MPa} & \sigma_{0}^{*}=1093 \mathrm{MPa} \\ \sigma_{\mathrm{E}_{0}}=107 \mathrm{MPa} & \sigma_{E_{\hat{v}}}=90 \mathrm{MPa}\end{array}$

to parameters for data measured below $300 \mathrm{~K}$ where the flow stress was measured at $2 \%$ strain while Part (b) gives the parameters for data obtained above $300 \mathrm{~K}$ where the flow stress was measured at $0.2 \%$ strain. The principal difference between these two sets of parameters lies only in $\sigma_{\mathrm{E}_{0}}$ which has a smaller value at the smaller strain i.e. above $300 \mathrm{~K}$. A lower $\sigma_{\mathrm{E}_{0}}$ also results in a lower total stress $\sigma_{0}$ as shown in the table.

The temperature dependence from $0 \mathrm{~K}$ to $900 \mathrm{~K}$ of the power law contribution to the strain-rate sensitivity is shown in Fig. 7. Note that this part of the strain-rate sensitivity is positive at all temperatures.

\section{The Dynamic Strain-Aging Contribution}

The DSA parameters are given in Table 2. The respective Snoek and Cottrell relaxation parameters $\tau_{\mathrm{s}}$ 


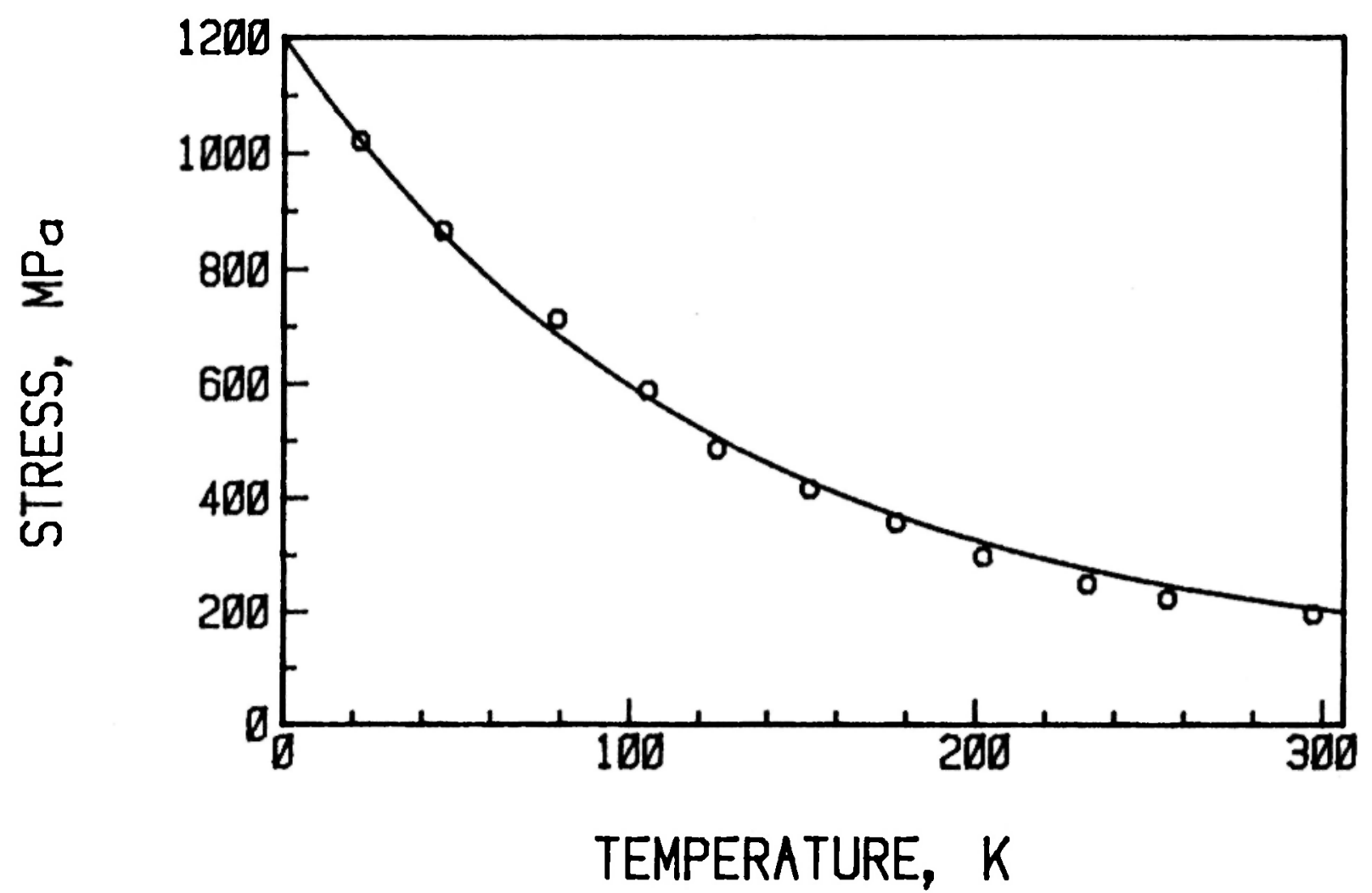

Fig. 5. The variation with temperature from 20 to $297 \mathrm{~K}$ of the $2 \%$ flow stress. Commercial purity niobium specimens of Fries et al. $/ 56 /$.

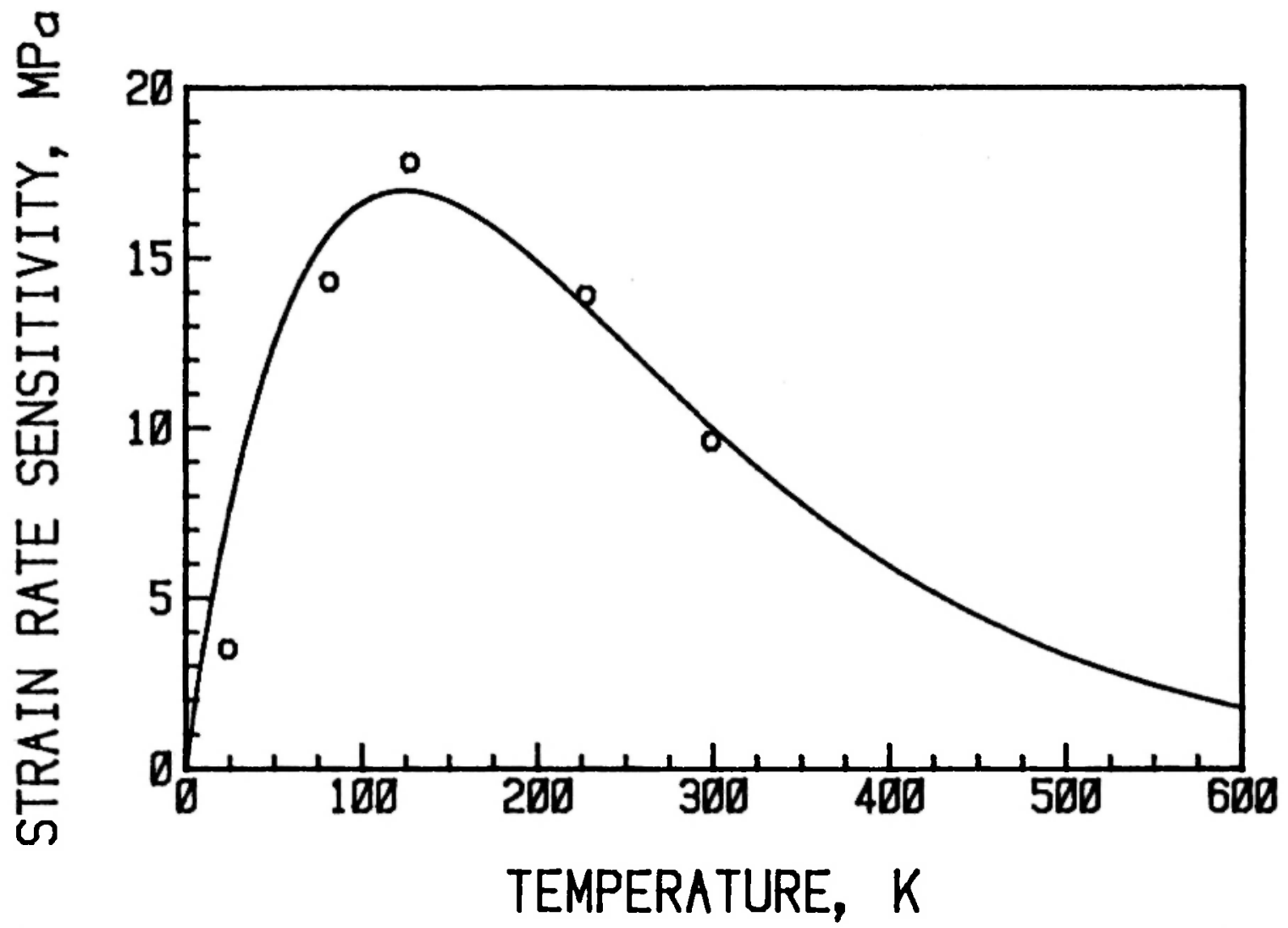

Fig. 6. The variation of the strain rate sensitivity with temperature. The data points were obtained by Friese et al. /56/ with their commercial purity niobium specimens. 


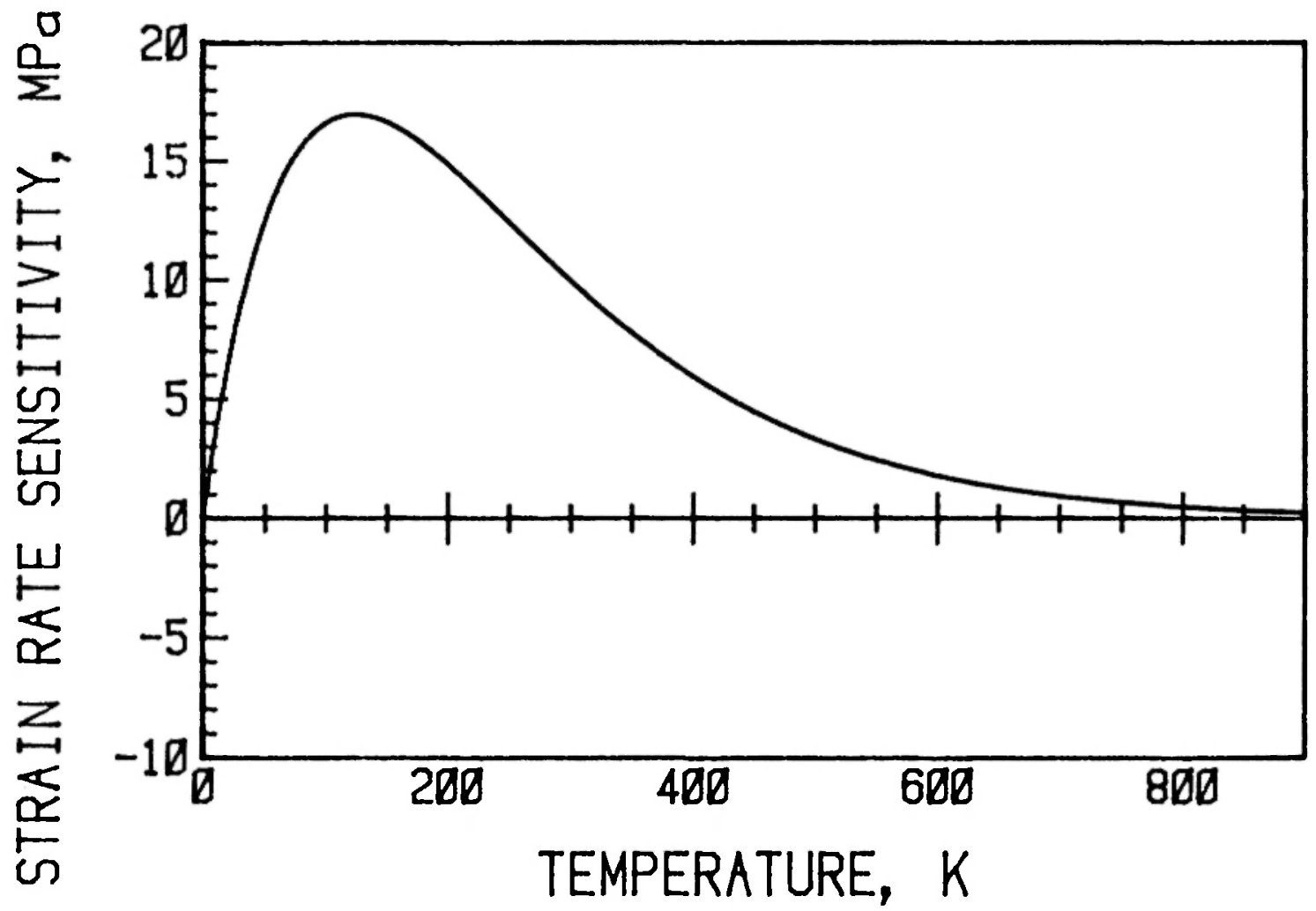

Fig. 7. The strain rate sensitivity due to the effective component of the flow stress, $\sigma^{*}$, from 0 to $900 \mathrm{~K}$. Note that this part of the strainrate sensitivity is positive at all temperatures.

and $\tau_{\mathrm{c}}$ were evaluated from the niobium-oxygen data of Delobelle, Oytana and Varchon /27/ and Boratto's $157 /$ diffusion equation for oxygen in niobium. The data of Delobelle et al. indicate a relaxation time for Snoek strain-aging of about $0.25 \tau_{\sigma}$ where $\tau_{\sigma}$ is the internal friction Snoek relaxation time. At the same time Delobelle et al. give $\tau_{\mathrm{c}}$ values that average about 5000 times their $\tau_{\mathrm{s}}$. Since both $\tau_{\mathrm{s}}$ and $\tau_{\mathrm{c}}$ exhibit activation energies close to that for the diffusion of oxygen in niobium, we may write

$$
\begin{aligned}
& \tau_{\mathrm{s}}=1.04 \times 10^{-15} \exp \frac{\left(1.103 \times 10^{5}\right)}{\mathrm{RT}} \mathrm{S} \\
& \tau_{\mathrm{c}}=5.3 \times 10^{-12} \exp \frac{\left(1.103 \times 10^{5}\right)}{\mathrm{RT}} \mathrm{S}
\end{aligned}
$$

where $Q=1.103 \times 10^{5}$ is in joules/mole and $R$ in joules $/$ mole ${ }^{\circ} \mathrm{K}$.

The waiting time, $t_{w}$, and the parameters, $\sigma_{s_{m}}^{0}$ and $\sigma_{c_{m}}$ were evaluated by trial and error. The dynamic recovery parameter $\alpha$, that determines the temperature dependence of $\sigma_{\mathrm{s}_{\mathrm{m}}}$ and $\sigma_{\mathrm{c}_{\mathrm{m}}}$ was taken as $8.2 \times 10^{-3}$. This gives the same temperature dependence to the DSA stress as that possessed by $\sigma^{*}$.
The non DSA stress between $300 \mathrm{~K}$ and $900 \mathrm{~K}$ is plotted as the upper curve in Fig. 8 using $\sigma=\sigma^{*}+\sigma_{\mathrm{E}}$. Figure 8 also shows the DSA stress in this temperature range plotted to the same scale. Combining the two stresses in Fig. 8 yields the curve in Fig. 9. Note the rather good fit between this calculated total stress curve and the experimental data points of Fries et al. which are also plotted on this figure. As will be pointed out later, the present theory becomes inadequate above about $600 \mathrm{~K}$ so that in this region a fit cannot be expected.

\section{The Dynamic Strain-Aging Contribution to the Strain-Rate Sensitivity}

The strain-rate sensitivity as given by Eq. (47), using the parameters in Tables 1 and 2 , is shown in Fig. 10 for the entire $0 \mathrm{~K}$ to $900 \mathrm{~K}$ temperature interval. A comparison of this curve with that in Fig. 7 clearly reveals the effects of DSA on the strain-rate sensitivity. Both the Snoek and Cottrell components add negative contributions to the strain-rate sensitivity when the strain-rate is increased as assumed in the present case. Note that for the parameters in Table 


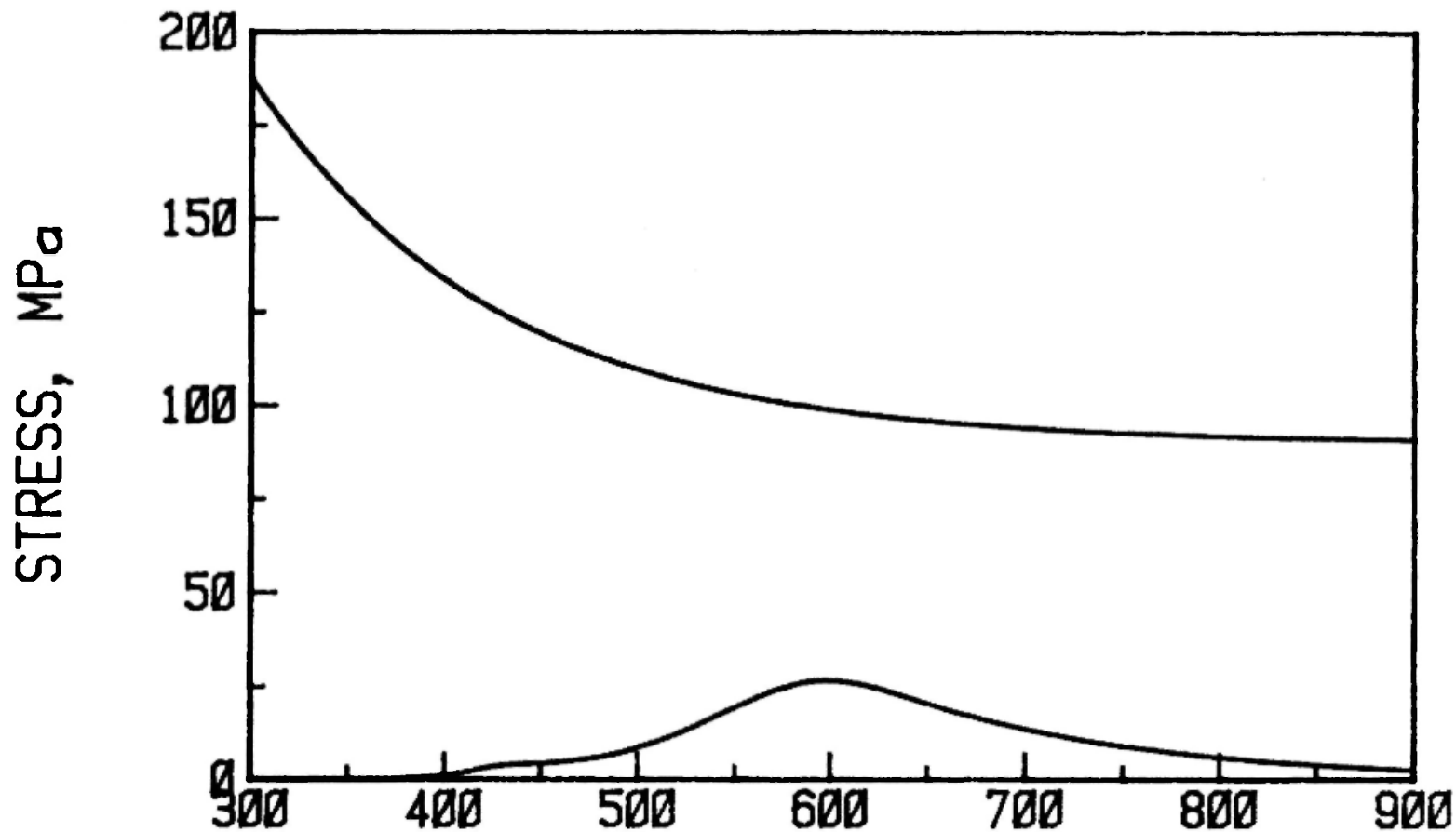

TEMPERATURE, $K$

Fig. 8. Showing the two major components of the flow stress plotted to the same scale. The lower curve represents the DSA part of the stress, the upper curve the non-DSA part composed of the sum of $\sigma^{*}$ and $\sigma_{\mathrm{E}}$.

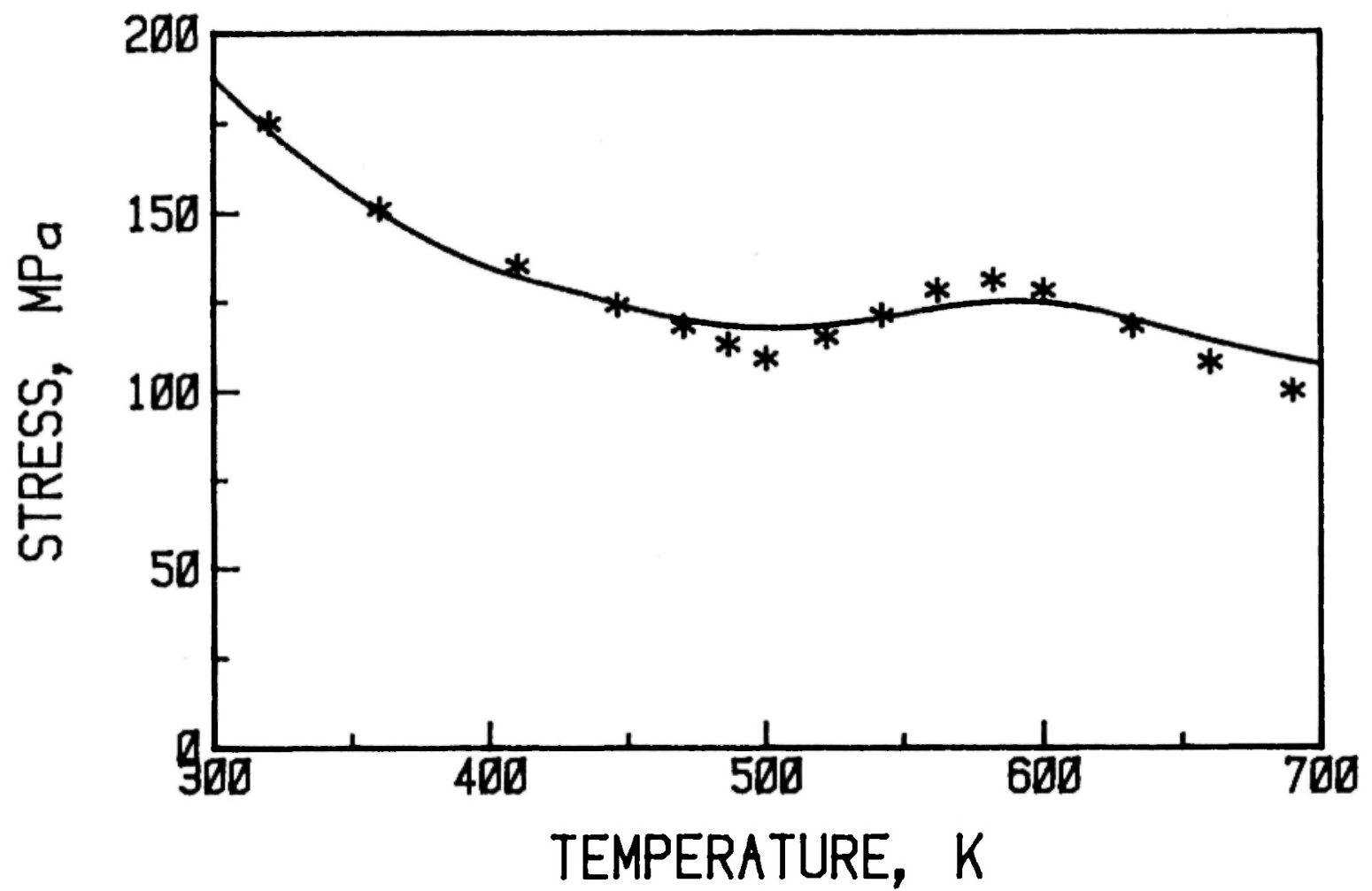

Fig. 9. The solid line curve gives the total stress or the sum of the two components shown in Fig. 8 for the temperature interval 300 to $700 \mathrm{~K}$. The data points are from the work of Friese et al. $/ 55 /$. 


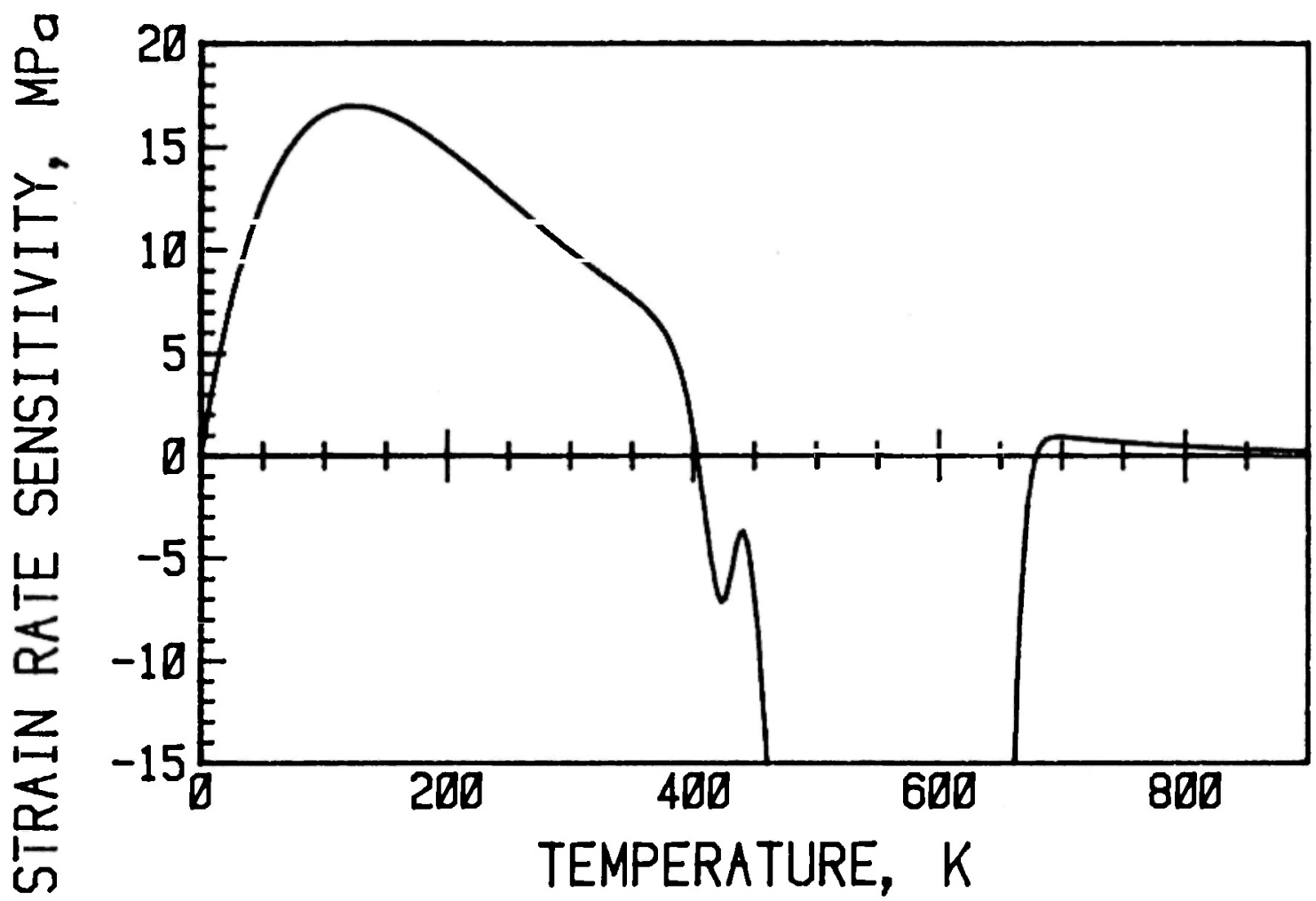

Fig. 10. The total strain rate sensitivity curve obtained when the DSA component is added to the non-DSA component in Fig. 7.

TABLE 2.

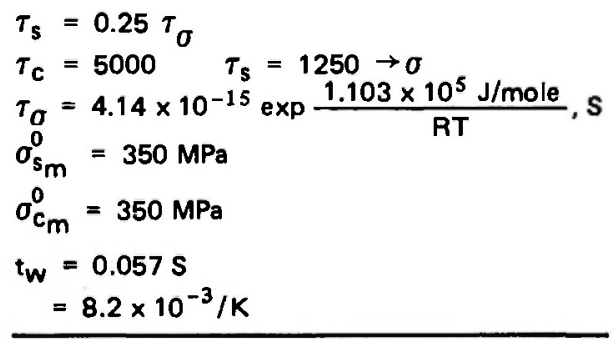

2, the Snoek component centred near $400 \mathrm{~K}$ is only moderatively negative. On the other hand, the Cottrell component produces a large negative strain-rate sensitivity betweeen approximately $450 \mathrm{~K}$ and $650 \mathrm{~K}$. This suggests that serrations due to the Snoek component of the DSA should probably not be observed, while serrations due to Cottrell aging would be expected. Fries, Cizeron and Lacombe /56/ report serrations for this material between $418 \mathrm{~K}$ and $623 \mathrm{~K}$. The predicted temperature range for serrations based on the region of Cottrell negative strain-rate sensitivity falls near the middle of the observed temperature range. The temperature range of the observed serrations, however, cannot be expected to match perfectly this calculated negative strain-rate sensitivity region. This is because Fig. 10 assumes a fixed strain, $\epsilon$, i.e. a constant mobile dislocation density $\rho_{\mathrm{m}}$, and a constant strain-rate $\dot{\epsilon}$. These conditions are equivalent to keeping $t_{w}$ fixed as the temperature is varied. However, in practice, a reported temperature range for the appearance of serrations is normally based on the observation of serrations at any point along the load elongation curves, including those parts of the curves associated with necking, which means that $t_{w}$ is not maintained constant. This is because the waiting time, $t_{w}$, is a function of the strain and is furthermore a function of $\dot{\epsilon}$ which can increase markedly in the deforming area once necking starts. To see this one needs only to consider the Orowan equation $\dot{\epsilon}=\phi \rho_{\mathrm{m}} \mathrm{b} \overline{\mathrm{v}}$ where $\dot{\epsilon}$ is the strain-rate, $\phi$ a Schmid orientation factor, $\rho_{\mathrm{m}}$ the mobile dislocation density and $\overline{\mathrm{v}}$ the average dislocation velocity, which we also assume can be written as $\bar{v}=L / t_{w}$, where $t_{w}$ is the waiting time and $L$ is the mean obstacle spacing. Thus, we have

$$
\mathrm{t}_{\mathrm{w}}=\frac{\phi \rho_{\mathrm{m}} \mathrm{bL}}{\dot{\epsilon}}
$$




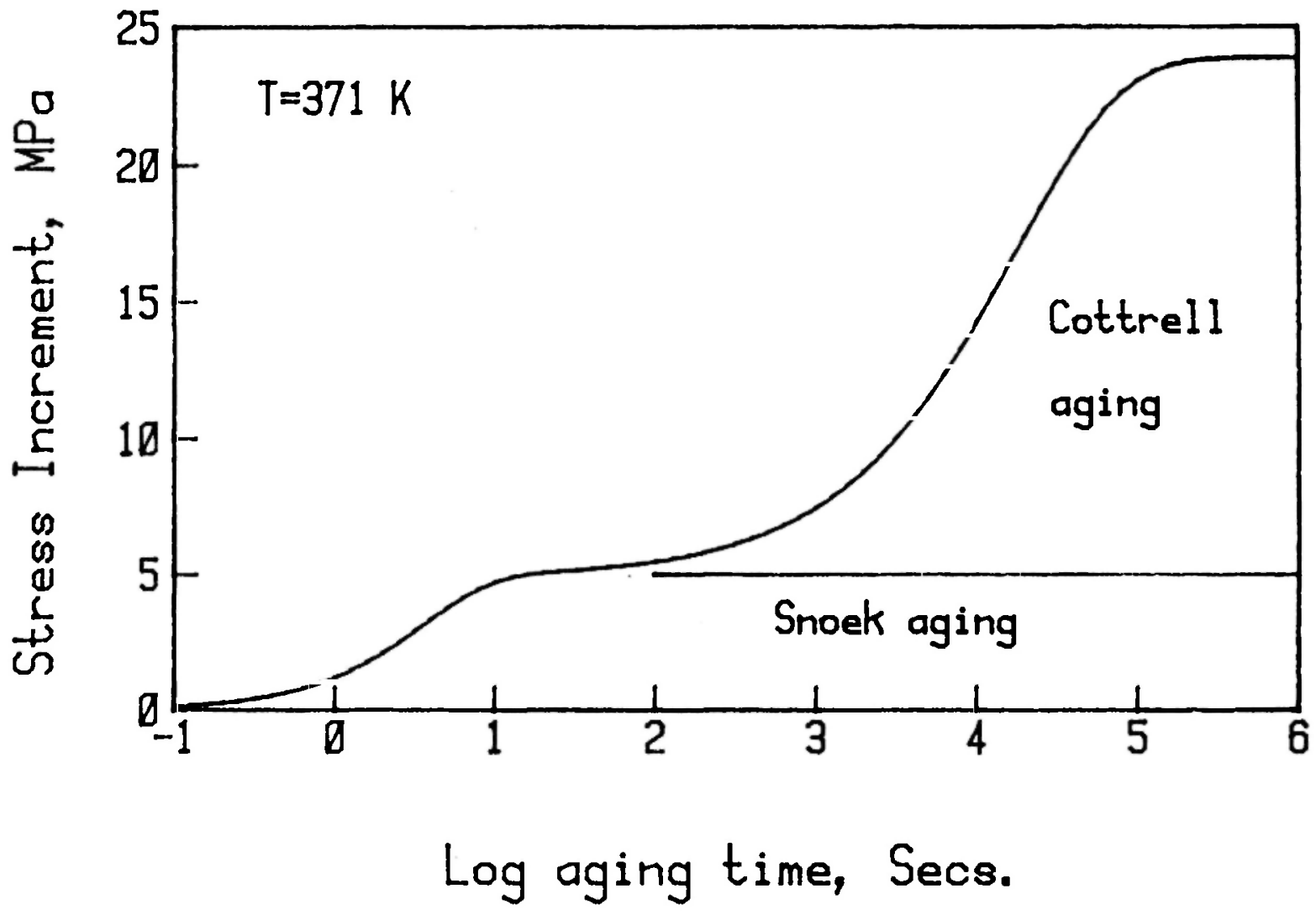

Fig. 11. The aging under stress strain aging kinetic curve expected when the prestrain strain-rate is very large, i.e. $t_{w} \approx 0$. After $/ 58 /$.

Accordingly, as $\rho_{\mathrm{m}}$ grows with increasing strain, $\mathrm{t}_{\mathrm{w}}$ must also increase. At the same time, once necking starts and $\epsilon$ increases, $\mathrm{t}_{\mathrm{w}}$ will decrease rapidly.

The fact that Fries et al. did not observe any serrations below $418 \mathrm{~K}$ implies, however, that serrations associated with Snoek dynamic strain-aging probably did not occur. This is consistent with the slightly negative strain-rate sensitivity at the Snoek strain-rate sensitivity minimum in Fig. 10. It is also supported by the oxygen level in their specimens, which was only $330 \mathrm{ppm}$. Serrations of the Snoek type normally appear $/ 25,59 /$ at larger oxygen concentrations.

\section{Strain-Aging Under Stress}

The model has also been successfully applied to aging under stress data $/ 58 /$. In experiments of this type tensile specimens are prestrained at a strain rate $\dot{\epsilon}_{1}$. When the desired strain is reached the load on the specimen is lowered to the aging load which is maintained for a period of time $t_{a}$. At the end of $t_{a}$ the specimen is restrained at $\dot{\epsilon}_{1}$. This normally produces a typical yield point with kinetics analogous to those observed in static strain aging. These kinetics can be described by the strain aging stress equation

$$
\begin{aligned}
& \Delta \sigma=\Delta \sigma_{s_{m}}\left\langle 1-\exp \left[-\left(\frac{t}{\tau_{s}}\right)\right]\right\rangle+ \\
& +\Delta \sigma_{c_{m}}\left\langle 1-\exp \left[-\left(\frac{t}{\tau_{c}}\right)^{2 / 3}\right]\right\rangle
\end{aligned}
$$

This basic equation was used earlier in developing Fig. 2 where the variation of $\Delta \sigma$ with $\mathrm{T}$ at constant $\dot{\epsilon}$ was considered. In that case, $t$ was assumed to equal $\mathrm{t}_{\mathrm{w}}$, a constant, and $\tau_{\mathrm{s}}$ and $\tau_{\mathrm{c}}$ to vary with the temperature. In the present case the temperature is fixed so that $\tau_{\mathrm{s}}$ and $\tau_{\mathrm{c}}$ are constants while $\mathrm{t}$ equals the variable aging time $t_{a}$. Figure 11 shows the form of the aging curve expected at $37 \mathrm{IK}$ under the condition that the prestrain strain rate $\epsilon$ is very rapid so that the waiting time during the prestrain is effectively zero. There are three basic parameters to be considered when strainaging is allowed to occur under stress. These are: 1. the time of aging under stress, $t_{a}, 2$. the waiting time, $t_{w}$, which is determined by the prestrain strain-rate, and 3. the waiting time, $t_{w_{a}}$, associated with the effective strain-rate during aging. Assuming Orowan's equation $\dot{\epsilon}=\phi \rho_{\mathrm{m}}$ bv and that $\rho_{\mathrm{m}}$ is a constant leads to a simple 


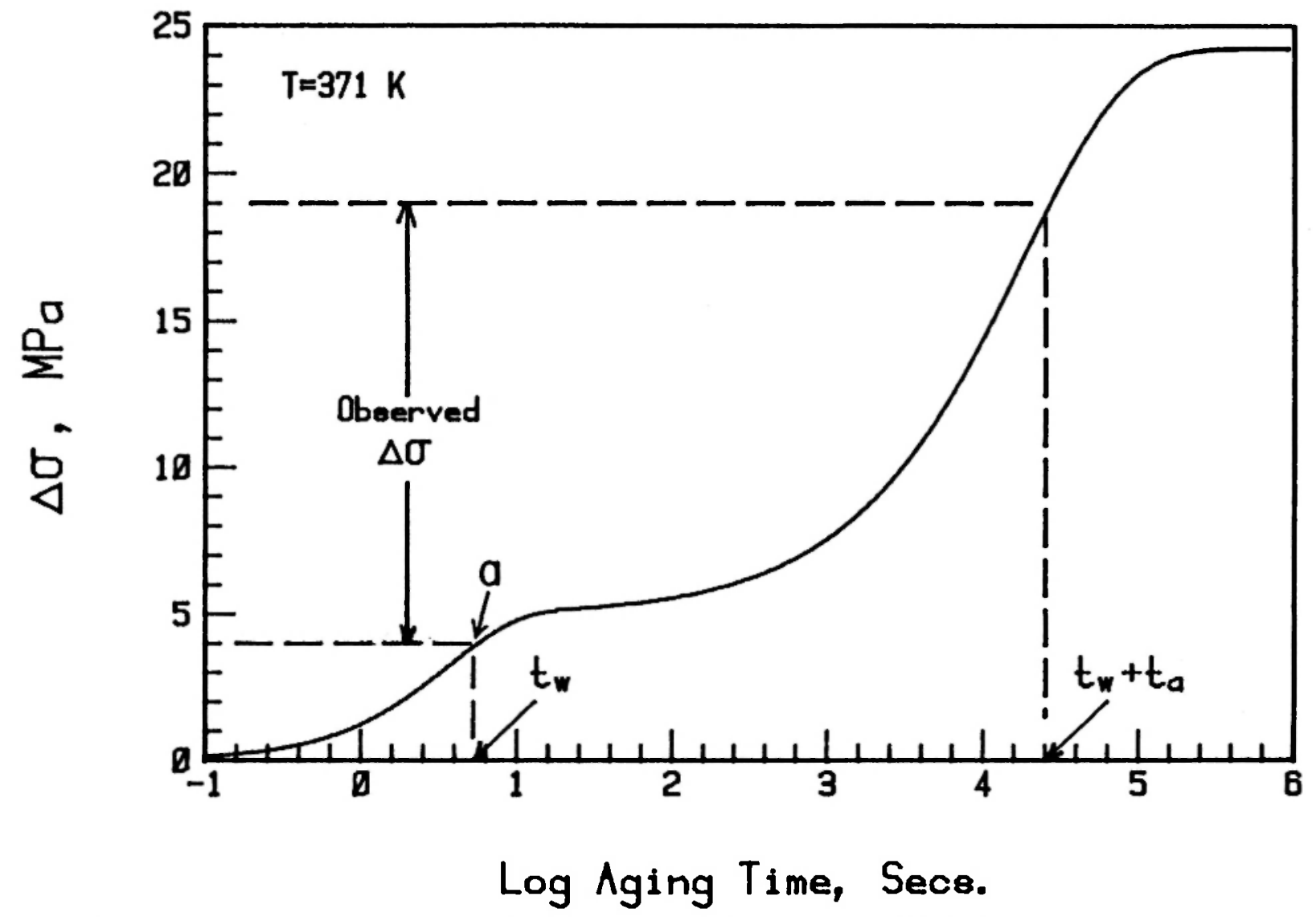

Fig. 12. Illustrating how a finite waiting time, $t_{w}$ during the prestrain influences the observed yield stress increment associated with an aging time $t_{a}$. After $/ 58 /$.

relationship between $t_{w_{a}}$ and $t_{w}$, i.e.,

$$
\mathrm{t}_{\mathrm{w}_{\mathrm{a}}}=\mathrm{t}_{\mathrm{w}}\left(\frac{\dot{\epsilon}_{1}}{\dot{\epsilon}_{\mathrm{a}}}\right)
$$

The effects of these three parameters on the return yield point can be deduced with the aid of Fig. 12 . In practice, during the prestrain $\dot{\epsilon}_{1}$ will not equal zero, and the dislocations will be subjected to a finite waiting time $t_{w}$, during which they become partially aged. If this is the case, then at the start of the aging under stress period the dislocations should find themselves at point "a" along the master relaxation curve in Fig. 12 corresponding to time $t_{w}$.

For simplicity it will now be assumed that the waiting time during aging under stress is longer than the maximum time used for the aging, i.e., $t_{w_{a}}>t_{a}$. Thus, the effective total aging time for the dislocations will be $t_{w}+t_{a}$. The expected rise in the flow stress that one should observe at the end of the aging under stress experiment is then the difference between that attained at $t_{w}$ and that attained at $t_{w}+t_{a}$. This is designated the "observed $\Delta \sigma$ " in Fig. 12 and can be evaluated /58/ using the equation

$$
\begin{aligned}
& \left.\Delta \sigma\left(\mathrm{t}_{\mathrm{a}}\right)=\Delta \sigma_{\mathrm{s}_{\mathrm{m}}} \exp \left[-\mathrm{t}_{\mathrm{w}} / \tau_{\mathrm{s}}\right)\right] \\
& \times\left\langle 1-\exp \left[-\left(\mathrm{t}_{\mathrm{a}} / \tau_{\mathrm{s}}\right)\right]\right\rangle+\Delta \sigma_{\mathrm{c}_{\mathrm{m}}}\left\langle\exp \left[-\left(\mathrm{t}_{\mathrm{w}} / \tau_{\mathrm{c}}\right)^{2 / 3}\right]\right. \\
& \left.\left.-\exp \left[-\left(\mathrm{t}_{\mathrm{w}}+\mathrm{t}_{\mathrm{a}}\right) / \tau_{\mathrm{c}}\right)^{2 / 3}\right]\right\rangle
\end{aligned}
$$

where $\Delta \sigma_{\mathrm{s}_{\mathrm{m}}}$ and $\Delta \sigma_{\mathrm{c}_{\mathrm{m}}}$ the Snoek and Cottrell amplitudes are assumed to be temperature dependent according to Eqs. (44).

Note that Eq. (57) has an effective maximum amplitude for the Snoek exponent equal to $\Delta \sigma_{\mathrm{s}_{\mathrm{m}}} \exp \left[-\left(\mathrm{t}_{\mathrm{w}} / \tau_{\mathrm{s}}\right)\right]$ which is the product of $\Delta \sigma_{\mathrm{s}_{\mathrm{m}}}$, the conventional Snoek amplitude, and an exponential factor whose argument involves the quotient of the prestrain waiting time $t_{w}$ and the Snoek strain aging relaxation time $\tau_{\mathrm{s}}$. This latter factor largely accounts for the fact that aging under stress data obtained at a fixed testing machine strain rate give kinetics curves that show a Snoek maximum amplitude that decreases rapidly with increasing temperature, as may be seen in Fig. 13 where the strain aging under stress data of Delobelle et al. /27/ are plotted. Note that at 398K 


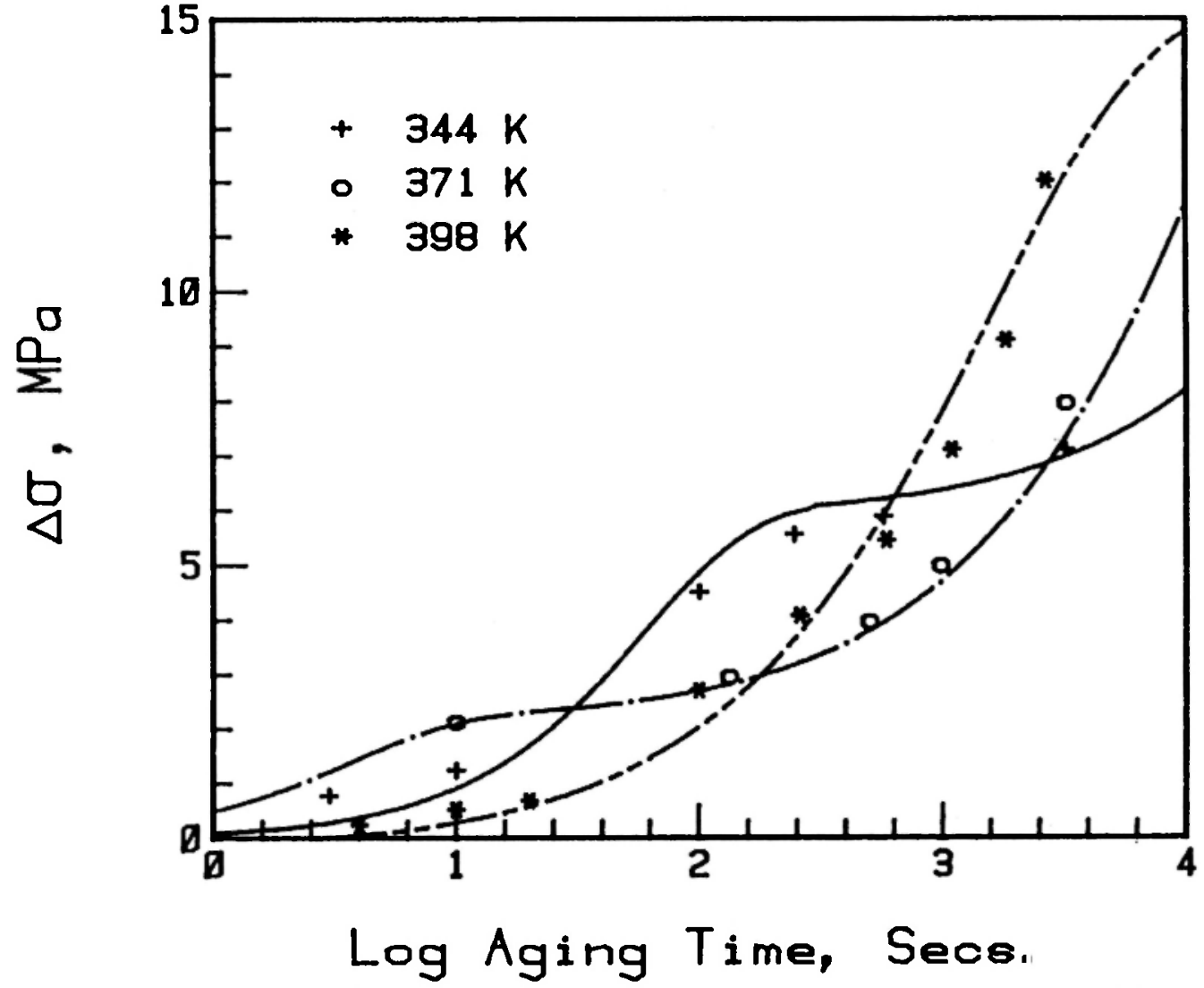

Fig. 13. Analytical yield point return curves for three temperatures are compared in this figure with the data of Delobelle et al./27/.

After $/ 58 \%$.

the Snoek plateau no longer exists. There is nothing mysterious about this tendency for the Snoek plateau to disappear with increasing temperature. It merely reflects the fact that for a given strain, specimens prestrained at a fixed strain rate should experience effectively the same $t_{w}$ or waiting time as the temperature is varied. On the other hand $\tau_{\mathrm{s}}$ will decrease with increasing temperature making the inherent pinning during the prestrain larger and larger. The yield point return as shown in Fig. 12 merely measures the increase in stress over and above this initial pinning. Thus if the Snoek pinning is saturated during the prestrain it will not appear as a component in aging under stress yield point data.

That Eq. 57 is able to successfully model the aging under strain data is also shown in Fig. 13 where the solid line curves were obtained /58/ with the use of this equation and the parameters listed in Table 3.

Equation (57) can also rationalize the fact that the aging under stress kinetics curves are affected by the size of the prestrain before aging. As pointed out by McCormick / $10 /$, under the condition of a constant strain rate, $t_{w}$ should be a function of $\epsilon^{\beta}$ where $\beta$ is a constant. Using this assumption it has been de-
TABLE 3

$$
\begin{aligned}
& t_{w}=3 \mathrm{~S} \\
& \tau_{\sigma}=4.14 \times 10^{-15} \exp \left[1.103 \times 10^{5} / \mathrm{RT}\right], \mathrm{s} \\
& \tau_{\mathrm{s}}=0.25 \tau_{\sigma} \\
& \tau_{\mathrm{c}}=5000 \tau_{\mathrm{s}} \\
& \Delta \sigma_{\mathrm{s}_{\mathrm{m}}}^{0}=8.75 \mathrm{MPa} \\
& \Delta \sigma_{s_{\mathrm{In}}}^{0}=34 \mathrm{MPa} \\
& \alpha=8.2 \times 10^{-3} / /^{\circ} \mathrm{K} \\
& \beta=1.2
\end{aligned}
$$

monstrated that a value of $\beta=1.2$ will make it possible to model the Delobelle et al. data $/ 27 /$ at $\mathrm{T}=$ $344 \mathrm{~K}$ for various prestrains. This is demonstrated in Fig. 14.

\section{FUTURE WORK TO EXPAND THE MODEL TO HIGHER TEMPERATURES}

The model currently works well for the $\mathrm{Nb}-\mathrm{O}$ and $\mathrm{Cu}-3.1 \mathrm{Sn}$ systems to about the upper limit of the Cottrell SRS minimum. Above this minimum the SRS rises and passes through a well defined peak which 


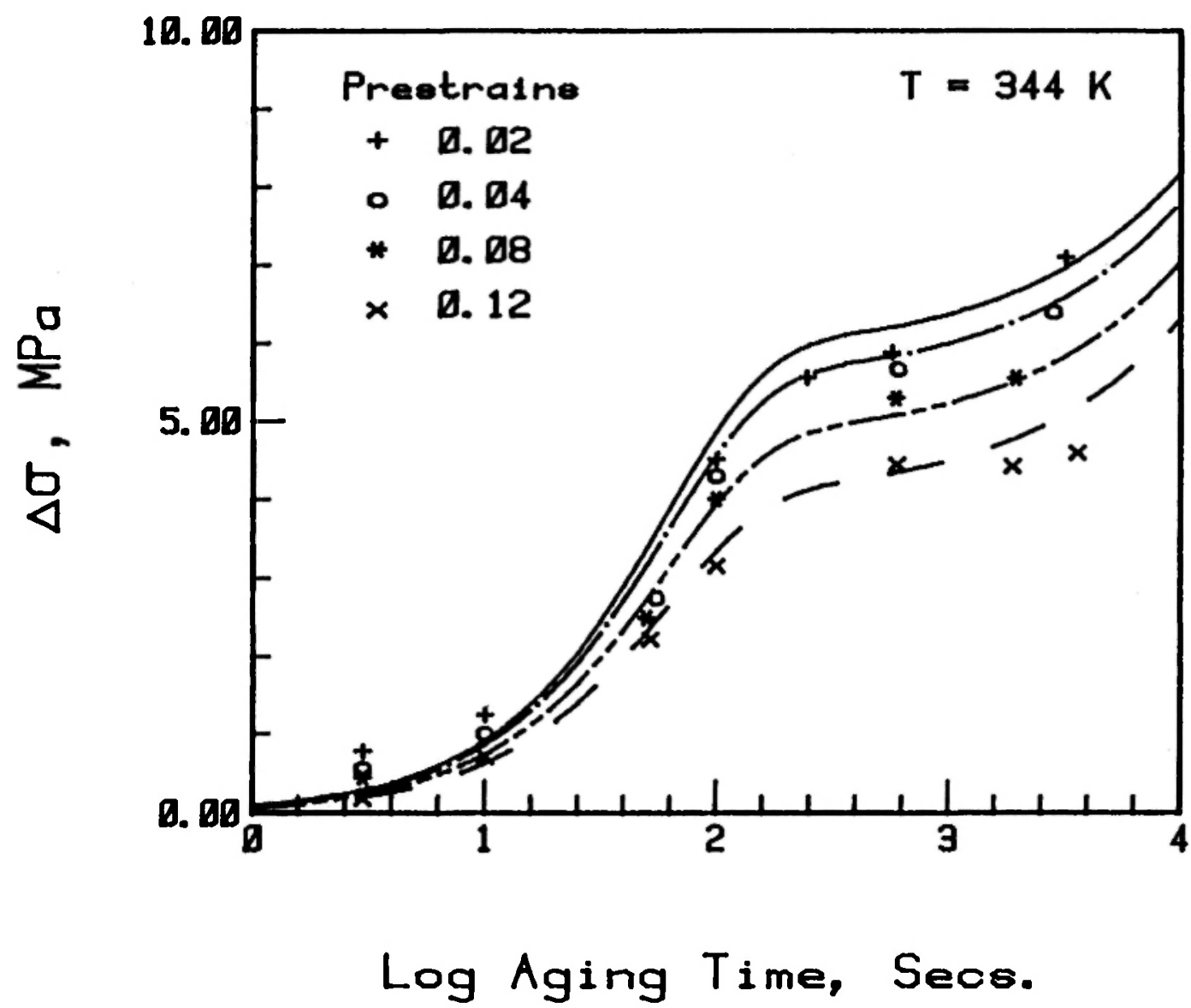

Fig. 14. Strain aging under stress kinetics curves corresponding to four prestrains between $2 \%$ and $12 \%$. Note that the curves obtained using Eq. 55 are able to account for the variations with prestrain in the Delobelle et al. experimental data /27/. After /58/.

can be observed in both $\mathrm{Nb}-\mathrm{O} / 59 /$ and $\mathrm{Cu}-3.1 \mathrm{Sn}$ $160 /$ data as shown in Figs. 15 and 16. This peak is apparently unexplained and is also not capable of being described with the aid of the present DSA model. We have also observed $/ 61 /$ this peak in a SRS versus temperature plot of mild steel data, and Yin, Doner and Conrad /62/ have shown such a peak in their Ti-O results.

An important question is why does the lower temperature model expressed by Eq. (47) not describe the SRS peak? The probable reason is that the model does not account for the very high mobility of the solute near the peak. Basically the model assumes that while the solute is mobile enough to pin dislocations as they wait for thermal activation, it is not mobile enough to interfere significantly with the motion of dislocations as they move from one obstacle to the next. Although this assumption is not rigorously correct in the lower temperature region where DSA phenomena are observed, it does not create serious problems. However, in the higher temperature region of the SRS maximum it apparently does not come close to reality. One is thus led to conclude that to explain the peak one needs to take a different approach, and we believe that this should be from the view of dislocation drag.

\section{DISLOCATION DRAG}

\section{Experimental Evidence in Support of Dislocation Drag}

In 1953 Cottrell /15/ suggested that experimental confirmation of dislocation drag is best looked for in slow creep (microcreep) experiments, and that Chalmer's work $/ 63 /$ on tin crystals should be particularly suitable for this purpose. Then in 1957 Weertman 164/ analyzed Gilman's results /65/ of a study of the creep of zinc crystals by prism slip. Weertman demonstrated that Gilman's observation that the strain rate in his specimens varied, as the third power of the stress could be explained in terms of dislocation drag. In the period from 1965-68 several papers /66-68/ appeared based on tensile test studies of $\mathrm{Al}-\mathrm{Mg}$ and $\mathrm{Al}-\mathrm{Cu}$ 


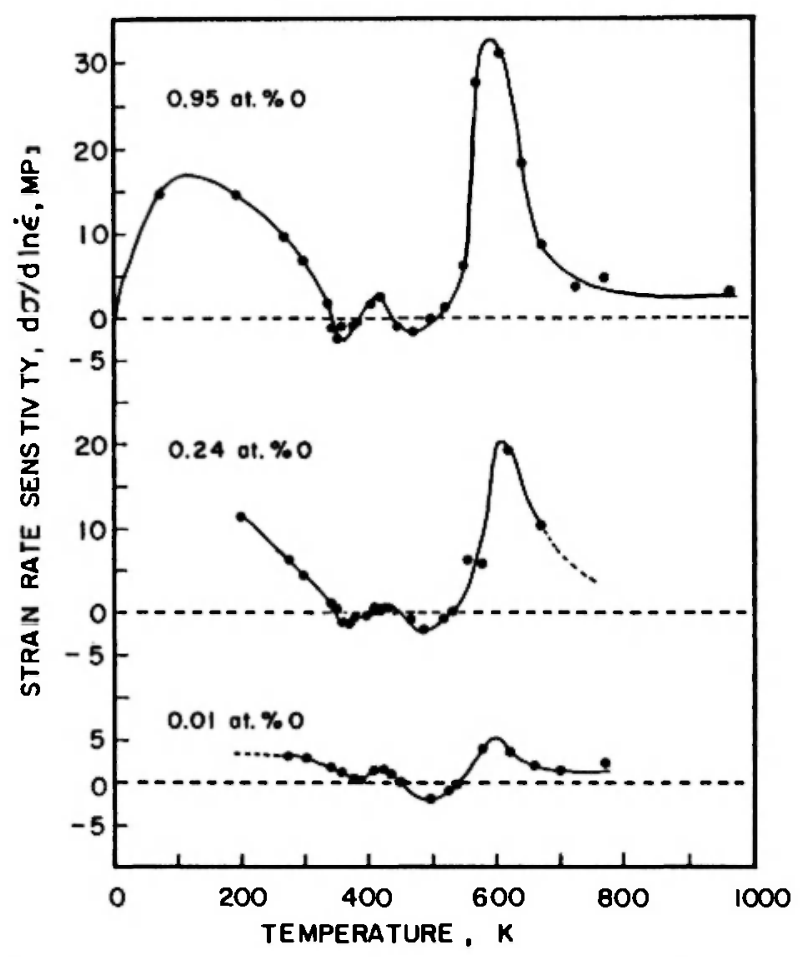

Fig. 15. Strain-rate sensitivity versus temperature curves for niobium containing three levels of oxygen. Note the strain rate sensitivity peak centered at about $600 \mathrm{~K}$. This peak cannot be explained by the present DSA theory. From /59/.

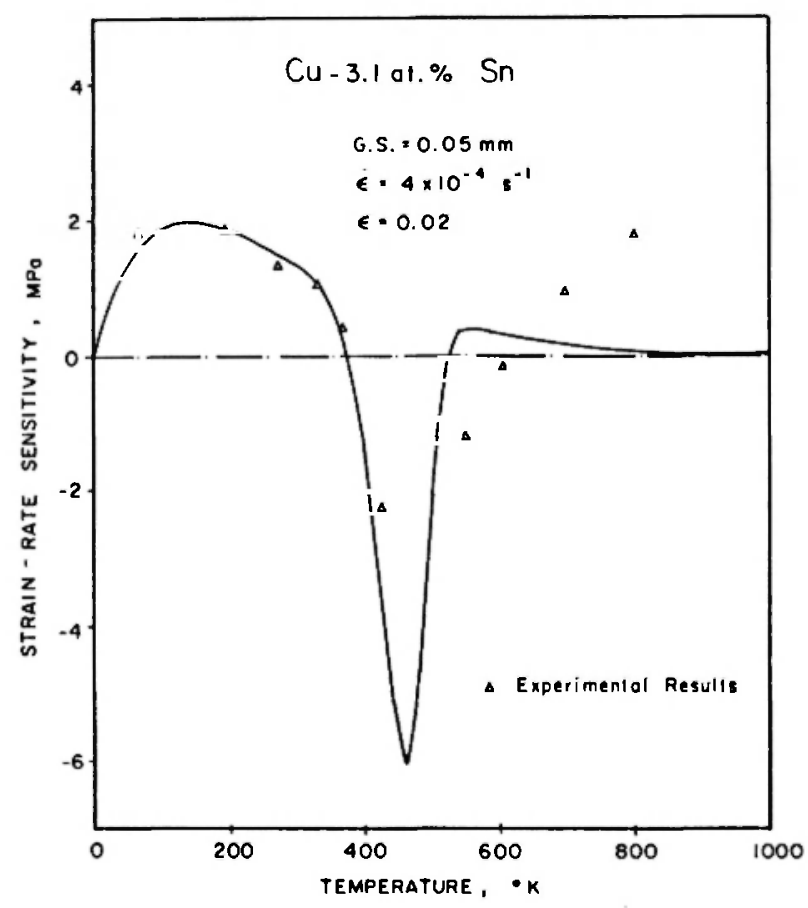

Fig. 16. Evidence for a high temperature strain-rate sensitivity peak in $\mathrm{Cu}-3.1$ at \% Sn. From /60/. alloys, in which data obtained between $623 \mathrm{~K}$ and $773 \mathrm{~K}$ (350 to $500 \mathrm{C}$ ) were interpreted as showing that the rate controlling process of deformation was the viscous motion of dislocations dragging solute atmospheres. Another paper $/ 69 /$ concerned with the tensile deformation of $\mathrm{Cu}-\mathrm{Zn}$ and $\mathrm{Cu}-\mathrm{Al}$ solid solutions made a similar conclusion for tests conducted between $500 \mathrm{~K}$ and $850 \mathrm{~K}$. All four of these latter papers /66-69/ were particularly concerned with a high temperature yield point that differs significantly from the sharp yield point due to strain aging, such as that observed in mild steel at room temperature. Their yield event had a number of unusual aspects; it appeared only at high temperatures, yielding occurred slowly instead of rapidly, it was apparently not associated with the formation of Lüders bands; the work hardening subsequent to yielding was very small, and the yielding phenomenon was independent of specimen grain size.

Because of the large strain rate sensitivity that exists in the temperature range where this form of yielding is observed, the consensus of these papers was that the yielding could be rationalized in terms of a Johnston 170/ mechanism of yielding with an initial dislocation density of the order of $10^{7}$. The strain rate controlling deformation mechanism was deduced to be dislocation drag for two basic reasons. First, the apparent activation energy associated with yielding was, in general, close to that for the diffusion of the solute. Second, the yield phenomenon depended on the presence of a solute in the metal, since the yield phenomenon was not observed in either pure copper or aluminum.

The above work has special significance with respect to the present work because this yielding phenomenon has also been observed in our $\mathrm{Nb}-\mathrm{O}$ and $\mathrm{Cu}-\mathrm{Sn}$ specimens in the temperature regime of the SRS peak. All of this work supports the assumption that the SRS peak is associated with deformation involving dislocation drag.

Another area where it has been felt that dislocation drag could be important is in explaining the PortevinLeChatelier effect. As pointed out by Yoshinaga and Morozumi /71/ the original work of Cottrell and Jaswon 172 / showed that the stress required to drag a dislocation solute atmosphere increased proportionally with the dislocation velocity when the velocity was small compared to the diffusing velocity of the solute atoms close to the dislocations. However, with increasing velocity of the dislocation the drag stress decreases because of a reduction in the size and concentration of the atmosphere. If it is assumed that dislocation drag is rate controlling, the plastic deformation in 
this higher velocity range should be unstable and result in discontinuous yielding. This view has been taken by Wilcox and Rosenfield /51/ and more recently by Yoshinaga and co-workers $/ 71,73,74 /$ who have made a detailed analysis of the possible role of dislocation drag in the Portevin-LeChatelier effect which they then applied to data obtained from specimens of vanadium containing oxygen. The more recent papers in which dislocation drag is considered as a viable deformation mechanism include two by Takeuchi and Argon /75-76/. In one of these /75/ published in 1976 these authors relate their dislocation drag predictions to creep data obtained with certain f.c.c. substitutional alloys. The authors conclude from this work that the resulting dislocation density and creep rate at the steady state showed fair agreement with the experimental results on their alloys.

The above summary indicates that on the whole there is strong support for the view that dislocation drag may be an important phenomenon in the temperature regime of the work hardening peak.

\section{Comments on the Role of Dislocation Drag in the Portevin-LeChatelier Effect}

The analysis of Yoshinaga et al. $/ 71,73,74 /$ shows that the mobility of the solute within the DSA interval is high enough to make dislocation drag a possible mechanism at these temperatures. However, in their approach to the problem of discontinuous plastic flow, dislocation drag was assumed to be rate controlling. It is our present feeling that at least in the DSA region dislocation drag is better considered as an effect superimposed onto a simple thermally activated mechanism. In other words one cannot simply consider dislocation drag as rate controlling in the DSA region.

\section{INCLUSION OF DISLOCATION DRAG THEORY IN. THE MODEL}

It is possible that a significant advance in our understanding of an important part of metal plasticity could result from a detailed development of the theory of plastic flow which considers;

1. Dislocations move discontinuously with the dislocations being forced to wait at obstacles for thermal activation in order to pass them.

2. While waiting at the obstacles the dislocations can be pinned by mobile solute atoms.

3. Upon the release of a dislocation from an ob- stacle, its motion up to the next obstacle is controlled by dislocation drag.

4. At a sufficiently high temperature dislocation drag may become rate controlling. In other words the effect on the stress of overcoming obstacles may be smaller than that due to the viscous motion of the dislocations.

With the present ability to model complex phenomena using computers the proposed analysis should be feasible. Not only does such an investigation have a potential to produce a better and more quantitative theory of DSA, but it is also expected to bring about a much better understanding of the factors determining the uniaxial flow stress at temperatures well above the DSA interval.

\section{REFERENCES}

1. LUBAHN, J.D., Trans. ASM, 44, 643 (1952).

2. COTTRELL, A.H., Phil. Mag, 44, 829 (1953).

3. COTTRELL, A.H., Vacancies and Other Point Defects in Metals and Alloys, Inst. Metals, London, 1 (1958).

4. HAM, R.K. and JAFFREY, D., Phil. Mag., 15, 247 (1967).

5. PORTEVIN, A. and LE CHATELIER, F., Trans. A.S.S.T. 5, 457 (1924).

6. MCCORMICK, P.G., Acto Met., 19, 463 (1971).

7. MACEWEN, S.R. and RAMASWAMI, B., Phil. Mag., 22, 1025 (1970).

8. MUKHERJEE, K., MAY, T., D'ANTONIO, C. and MACIAG, R., Met. Trans., 1, 3233 (1970).

9. SOLER-GOMEZ, A.J.R. and TEGART, W.J.MCG., Phil. Mag., 20, 495 (1969).

10. MCCORMICK, P.G., Acto Met., 20, 351 (1972).

11. MCCORMICK, P.G., Acta Met., 21, 873 (1973).

12. MCCORMICK, P.G., Acta Met., 22, 489 (1974).

13. SLEESWYK, A.W., Acto Met., 6, 598 (1958).

14. COTTRElL, A.H. and BILBY, B.A., Proc. Phy. Soc. A, 62A, 49 (1949).

15. COTTRELL, A.H., Dislocations and Plastic Flow in Crystals, Oxford Univ. Press (1953).

16. FLEISCHER, R.L., Acta Met., 11, 203 (1963).

17. VAN DEN BEUKEL, A., Phys. Stat. Sol, (a), 30, 197 (1975).

18. VAN DEN BRINK, S.H., VAN DEN BEUKEL A. and MCCORMICK, P.G., Phys. Stat. Sol (a), 30, 469 (1975).

19. VAN DEN BEUKEL, A., Acto Met., 28, 965 (1980).

20. FRIEDEL, J., Dislocations, Pergamon Press, Oxford, 405 (1964).

21. BALDWIN, D.H and REED-HILL, RE., TMS-AIME, 242, 661 (1968).

22. SOO, P. and HIGGINS, G.T., Acta Met., 16, 177 (1968).

23. HAASEN, P. and KELLEY, A, Acto Met., 5, 192 (1957).

24. BOLLING, G.F., Phil. Mag., 4, 537 (1959).

25. BECKERMAN, L.P., Ph.D. Dissertation, University of 
Florida (1980).

26. BECKERMAN, L.P. and REED-HILL, R.E., Proc. 5th Intl. Conf. on the Strength of Metals and Alloys, P. Haasen, V. Gerold and G. Kostorz, Eds, Pergamon Press, Oxford, 535 (1979).

27. DELOBELLE, P., OYTANA, C. and VARCHON, D., Mat. Sci. Eng., 29, 261 (1977).

28. DELOBELLE, P. and OYTANA, C., Scripta Met., 12, 765 (1978).

29. EVANS, J.T. and DOUTHWAITE, R.M., Acta Met., 21, 49 (1973).

30. ROSINGER, H.E., Met. Sci, 9, 1 (1975).

31. NAKADA, Y. and KEH, A.S., A cta Met., 15, 879 (1967).

32. WILSON, D.V. and RUSSELL, B., Acta Met., 7, 628 (1959).

33. ROSINGER, H.E., CRAIG, G.B. and BRATINA, W.J., Mat. Sci. Eng., 5, 163 (1969/1970).

34. ROSINGER, H.E. and CRAIG, G.B., Can. Met. Quart., 8, 97 (1969).

35. REED-HILL, R.E., Proc. Intl. Conf. on Dislocation Modelling of Physical Systems, M.F. Ashby, R. Bullough, C.S. Hartley and J.P. Hirth, Eds., Acta Metallurgica Inc., Oxford, 163 (1981).

36. HARPER, S., Phys. Rev., 83, 709 (1951).

37. BUllough, R. and NEWMAN, R.C., Proc. Roy. Soc., A249, 427 (1959).

38. BUllough, R. and NEWMAN, R.C., Proc. Roy. Soc., A266, 209 (1962).

39. Bullough, R and NEWMAN, R.C., Acta Met., 10, 971 (1962).

40. HALL, E.O., Yield Point Phenomena in Metals and Alloys, Plenum Press, New York, 55 (1970).

41. HARTLEY, C.S., Acta Met., 14, 1237 (1966).

42. AHLERS, M., Met. Trans., 1, 2415 (1970).

43. SEEGER, A., Phil. Mag., 1, 651 (1956).

44. SCHOECK, G. and SEEGER. A, Defects in Crystalline Solids, Phys. Soc. London, 340 (1955).

45. PREKEL, H.L, LAWLEY, A. and CONRAD, H., Acta Met., 16', 337 (1968).

46. QIAN, K.W. and REED-HILL, R.E., Scrpita Met., 16, 807 (1982).

47. COTTRELL, A.H, Jour. Mech. Phys. Solids, 1, 53 (1952).

48. SEEGER. A., Dislocations and Mechanical Properties of Crystals, (J.C. Fisher, W.G. Johnston, R. Thomson and T. Vreeland, Jr., Eds.), John Wiley, New York, 243 (1957).

49. CONRAD, H., HAYS, L, SCHOECK, G. and WIEDERSICH, H., A cta Met., 9, 367 (1961).

50. ROSEN, A. and BODNER. S.R., J. Mech. Phys. Solids, 15, 47 (1967).
51. WILCOX, B.A. and ROSENFIELD, A.R., Mater. Sci. Eng., 1, 201 (1966).

52. DECERF, J., Z. Metallk, 65, 215 (1974).

53. MCCORMICK, P.G., A cta Met., 19, 463 (1971).

54. MULFORD, RA. and KOCKS, U.F., Acta Met., 27, 1125 (1979).

55. FRIES, J.F., HOUSSIN, B., CIZERON, G. and LACOMBE, P., Jour. Less-Com. Met., 33, 117 (1973).

56. FRIES, J.F., CIZERON, C. and LACOMBE, P., Rev. de Phy. Appl, 5, 371 (1970).

57. BORATTO, F.J.M. and REED-HILL, R.E., Met. Trans. A., 8A, 1233 (1977).

58. REED-HILL, R.E., PARK, S.C and BECKERMAN, L.P., Acta Met., 31, 1715 (1983).

59. PARK, S.C., BECKERMAN, L.P. and REED-HILL, RE., Met. Trans. A., 14A, 463 (1983).

60. QIAN, K.W. and REED-HILL, R.E., Acta Met., 31, 87 (1983).

61. REED-HILL, R.E., unpublished research, Dept. Materials Science and Engineering, University of Florida, Gainesville, FL 32611.

62. YIN, C., DÖNER M. and CONRAD, H., Met. Thans. A., 6A, 1901 (1975).

63. CHALMERS, B., Proc. Roy. Soc., A156, 427 (1936).

64. WEERTMAN, J., J. App. Phys, 28, 1185 (1957).

65. GILMAN, J., J. Metals, 8, 1326 (1956).

66. HORIUCHI, R, YOSHINAGA, H. and HAMA, S., Thans. Jap. Inst. Met., 6, 123 (1965).

67. HORIUCHI, $\mathrm{R}$. and YOSHINAGA, H, Trans. Jap. Inst. Met, , 6, 131 (1965).

68. ASADA, H., HORIUCHI, R, YOSHINAGA, H. and NAKAMOTO, S., Trans. Jap. Inst. Met., 8, 159 (1967).

69. ASANO, M, IZUMI, O. and TANAKA, E., Trans. Jap. Inst. Met., 9, 349 (1968).

70. JOHNSTON, W.G., J. Appl Phys., 33, 2716 (1962).

71. YOSHINAGA, H. and MOROZUMI, S., Phil. Mag., 23, 1351 (1971).

72. COTTRELL, A.H. and JASWON, M.A., Proc. Roy. Soc. A., 199, 104 (1949).

73. YOSHINAGA, H. and MOROZUMI, S., Phil. Mag., 23, 1367 (1971).

74. YOSHINAGA, H., TOMA, K., ABE, K. and MOROZUMI, S., Phil. Mag., 23, 1387 (1971).

75. TAKEUCHI, S. and ARGON, A.S., Acta Met., 24, 883 (1976).

76. TAKEUCHI, S. and ARGON, A,S., Phil Mag. A., 40. 65 (1979). 